\title{
A Most Egalitarian Profession: Pharmacy and the Evolution of a Family-Friendly Occupation
}

\section{Citation}

Goldin, Claudia, and Lawrence F. Katz. 2016. "A Most Egalitarian Profession: Pharmacy and the Evolution of a Family-Friendly Occupation." Journal of Labor Economics 34 (3) (July): 705-746. doi:10.1086/685505.

\section{Published Version}

doi:10.1086/685505

\section{Permanent link}

http://nrs.harvard.edu/urn-3:HUL.InstRepos:33973831

\section{Terms of Use}

This article was downloaded from Harvard University's DASH repository, and is made available under the terms and conditions applicable to Other Posted Material, as set forth at http:// nrs.harvard.edu/urn-3:HUL.InstRepos:dash.current.terms-of-use\#LAA

\section{Share Your Story}

The Harvard community has made this article openly available.

Please share how this access benefits you. Submit a story.

\section{Accessibility}




\title{
A Most Egalitarian Profession: Pharmacy and the Evolution of a Family-Friendly Occupation
}

\author{
Claudia Goldin, Harvard University and National \\ Burean of Economic Research
}

\author{
Lawrence F. Katz, Harvard University and National \\ Bureau of Economic Research
}

\begin{abstract}
Pharmacy today is a highly remunerated female-majority profession with a small gender earnings gap and low earnings dispersion. Using extensive surveys of pharmacists, as well as the US Census, American Community Surveys, and Current Population Surveys, we explore the gender earnings gap, penalty to part-time work, demographics of pharmacists relative to other college graduates, and evolution of the profession during the last half-century. Technological changes increasing substitutability among pharmacists, growth of pharmacy employment in retail chains and hospitals, and related decline of independent pharmacies reduced the penalty to part-time work and contribute to the narrow gender earnings gap in pharmacy.
\end{abstract}

We are grateful to the Midwestern Pharmacy Research Consortium, especially John Schommer at the University of Minnesota, College of Pharmacy, and Akeem A. Yusuf now at the Minneapolis Medical Research Foundation, for making the merged data of the National Pharmacist Workforce Surveys available to us. We thank seminar and conference participants at Harvard University, the 2013 SOLE meetings, and the Yrjö Jahnsson Foundation 2014 Congress in Helsinki, Finland, especially our discussant David Dorn. Tanya Avilova, Jane Lee, Natalia Emanuel and especially Chenzi $\mathrm{Xu}$ ably helped with data cleaning and other parts of this project. Contact the corresponding author, Larry Katz, at lkatz@harvard.edu. Information concerning access to the data used in this article is available as supplementary material online.

Correction: This article was reposted on July 21, 2016 to correct an error in figure 4.

[Journal of Labor Economics, 2016, vol. 34, no. 3]

(C) 2016 by The University of Chicago. All rights reserved. 0734-306X/2016/3403-0007\$10.00

Submitted August 25, 2013; Accepted February 23, 2015; Electronically published April 11, 2016 


\section{Introduction: Evolution of a Family-Friendly Occupation}

Employee demand for temporal flexibility has grown, particularly among women. How can a firm, industry, or sector employ highly paid professionals and grant them temporal flexibility without a substantial wage penalty? We show that the occupation of pharmacist changed during the last half-century and became a family-friendly profession with a high fraction of women and an ability to work part-time with little or no hourly wage penalty. The reasons concern a set of technological changes that enhanced the substitutability of one pharmacist for another and decreased self-employment among pharmacists.

As the fraction female increased, the (full-time equivalent) earnings of pharmacists relative to comparable professionals rose-not fell-for both men and women. As illustrated in figure 1, from 1970 to 2010, median earnings of full-time, year-round pharmacists increased relative to physicians, lawyers, and veterinarians. In addition, the ratio of female to male pharmacist earnings rose substantially. The female to male ratio for median annual earnings of full-time, full-year workers grew from 0.66 in 1970 to 0.92 in 2010. The current gender earnings gap in pharmacy is now smaller than in almost any other high-wage profession.

Earnings among pharmacists are currently high, and they largely differ by hours of work. Managers, and even owners, earn more than employee pharmacists largely because they work more hours. Women with children earn less largely because they work fewer hours. Pharmacy earnings today are highly linear in hours, and therefore pharmacy has a relatively low career cost of family (Goldin and Katz 2011). But in 1970 pharmacists who worked longer hours made significantly more, the self-employed were far more highly remunerated, and women with children earned far less than those without children, even holding hours constant.

Pharmacists' hourly earnings today exhibit very low dispersion, especially considering the high mean. Because of the extensive work flexibility and low pecuniary penalty to short hours, female pharmacists with currently active licenses take little time off during their careers even when they have children. ${ }^{1}$ In all of these ways, pharmacy has become one of the most egalitarian of US professions.

We begin by detailing three production and health-care changes that are the forces behind the evolution of the pharmacy sector. We provide a brief history of the supply side of the pharmacy sector and long-term trends in practice settings, fraction female, earnings, gender pay gap, and hours. The

${ }^{1}$ Knapp et al. (1992) analyze the results of a retrospective survey given to all living graduates of a Midwestern pharmacy school. The use of graduating cohorts, rather than just those with active pharmacy licenses, allows them to measure the shift out of pharmacy as well as out of the labor force. Labor force participation rates of women with pharmacy degrees were substantial at all ages (90\%-97\%). 


\section{A. Males}

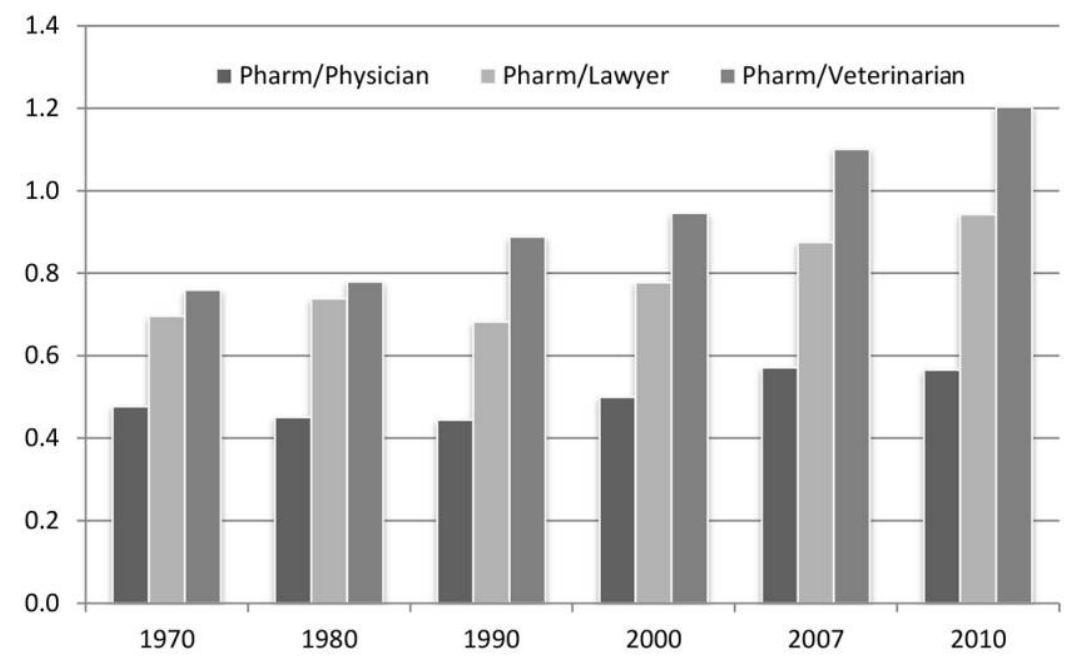

\section{B. Females}

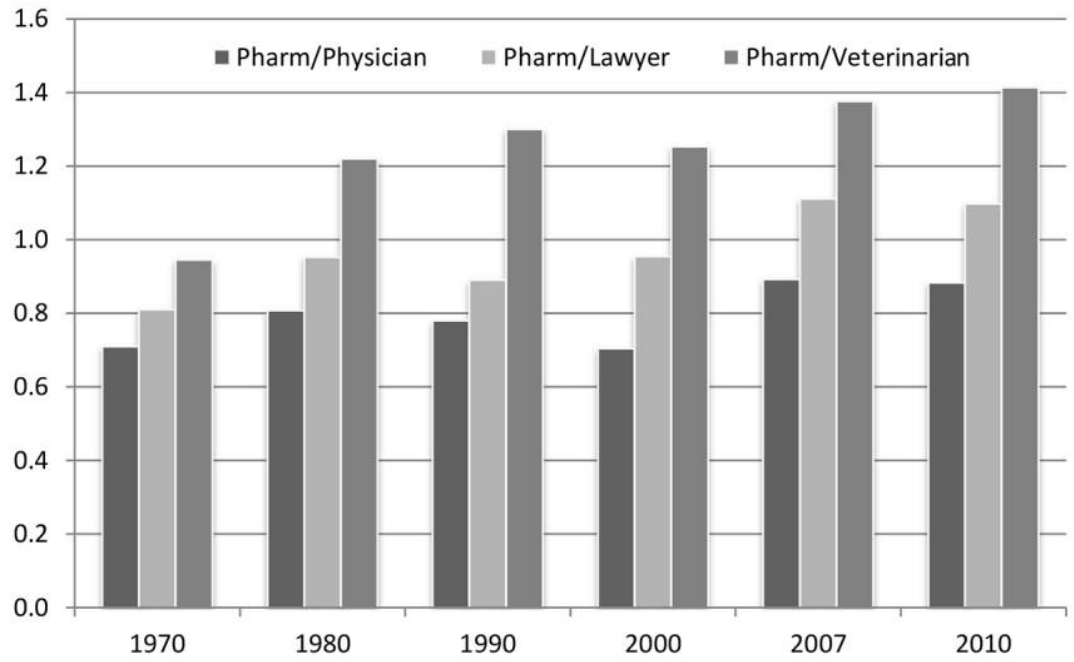

FIG. 1.-Median earnings of full-time, year-round pharmacists relative to other professions, 1970-2010, by sex. Sources: 1970-2000, US Census of Population, public use samples; 2006-2011, American Community Survey (ACS) public use samples; 1970 , aggregate six $1 \%$ samples. The $1980-2000$ are $5 \%$ samples. The 2006-10 ACS are 1\% samples each year. 2007 is the average of 2006, 2007, and 2008; 2010 is the average of 2009, 2010 and 2011. NoTE: Earnings is the sum of wage and salary, business, and farm incomes. The samples are restricted to 25-64-yearold full-time ( 35 or more hours per week) and full-year ( 40 or more weeks per year) workers. 
sector today is discussed next: the income levels, income dispersion, and hours make it among the most egalitarian professions. We then address why the gender gap in earnings narrowed and is currently low and the role of the linearity of pay with regard to hours. Using data from 1970 and 2010, we estimate changes in pharmacist earnings with regard to hours, self-employment, industry, and family composition. We use a compensating differentials framework to show how the three changes, by enhancing substitutability among pharmacists and greatly reducing the premium to ownership, are largely responsible for the time trends and the current state of the profession. We end with a discussion of the lessons for other professions and why some are similar and some are very different.

\section{Technological, Scale, and Production Changes That Shaped the Evolution}

The pharmacy sector was not always family friendly and egalitarian. Ever since the 1970s, the sector has been transformed by three related long-run changes. ${ }^{2}$

The first is an increase in the scope and scale of drug stores. These changes produced an increase in corporate ownership of pharmacies (e.g., CVS, Walgreens, and Rite-Aid), a decrease in owner-operated pharmacies, and a decrease in the fraction of pharmacists working in independent pharmacies. ${ }^{3}$ Changes in the health-care sector have led to an increase of pharmacists who work in hospitals and an increase, more recently, in pharmacists working in mail-order pharmacies.

The second change is the extensive use of information technology systems and an increase in prescription drug insurance, which have both enhanced the ability of pharmacists to hand off clients. Improvements in information technology have enhanced the ability of pharmacists to leave a coherent and comprehensive record of each client, increasing the substitutability of pharmacists and reducing consumer preferences for particular pharmacists. Because of the increase in insurance coverage, pharmacists can access the prescriptions of clients through Pharmacy Benefit Managers (PBM) even if the scripts were not filled at that pharmacy. ${ }^{4}$

${ }^{2}$ Because the changes are technological, they should have similar impacts across countries. Regulations, however, differ widely, and many nations protect "community" (non-publicly traded) pharmacies. On changes in the United Kingdom that are similar to those in the United States, see Bottero (1992). For a discussion of quotas and other restrictions in France, see Bourdon, Ekeland, and Brion (2008). For a comparison of Spain, which requires that pharmacies be owned by the pharmacist, and the United Kingdom, which does not, see Lluch and Kanavos (2010).

3 "Independent" pharmacies are either standalone or have few stores and are not publicly traded corporations. "Community" pharmacies are generally independents.

${ }^{4}$ The pharmacy industry's layers are many and include manufacturers, wholesalers, insurers (including the government), and Pharmacy Benefit Managers. Most 
The third change is the standardization of pharmacy products and services. Medications have been increasingly produced by pharmaceutical companies rather than being compounded in individual pharmacies and hospitals. The greater standardization of medications has meant that the idiosyncratic expertise and talents of a particular pharmacist have become less important.

The first set of changes increased the fraction of pharmacists who are employees and managers in the corporate sector and decreased the fraction who are self-employed and work for independent practices. The other two changes make pharmacists better substitutes for each other and enable an almost costless handoff of clients. ${ }^{5}$

Structural changes in pharmacy (and for similar reasons in professions such as optometry) were rooted in major shifts in retailing in America and elsewhere in the world that increased the benefits of large scale. It would be hard to assign credit for the spread of Wal-Mart, Target, Costco, CVS, Rite Aid, Walgreens, and other chains that have pharmacies to the particularities of the pharmacy industry or to women's increased numbers in the profession.

\section{Historical Trends in the Pharmacy Sector}

\section{A. Long-Run Sectoral Changes}

Using a large number of sources, we have pieced together a history of the pharmacy sector that shows a decline in the fraction of pharmacists in independent practice and an increase of those employed in chain stores and hospitals. Time trends also show the increase of women in the profession and an upsurge in the relative earnings of women to men.

Pharmacists today are found in a variety of sectors, although retail sales (independent plus other retail pharmacies) and hospitals together account for almost $90 \%$ across all years (see table 1, cols. 1-3). In 1966, $83 \%$ of pharmacists worked in retail sales and $8 \%$ in hospitals, but by $2009,59 \%$ of them worked in retail sales and $30 \%$ in hospitals. The relative increase of pharmacists working in hospitals has reinforced two other trends apparent in table 1, namely, the increase of pharmacists as employees rather than as owners (col. 4) and the decrease in the fraction working in independent practice (col. 1).

For the most recent years shown, about $5 \%$ of pharmacists were selfemployed (owners or partners), whereas more than $35 \%$ were selfemployed in 1970 and 40\% were in 1966 (see table 1, col. 4). For those

of these layers are fairly concentrated, and some have overlapping ownership. The largest PBMs are Express Scripts and CVS Caremark.

${ }^{5}$ See Goldin (2014) on the importance of handoffs in a model of temporal flexibility and earnings. 


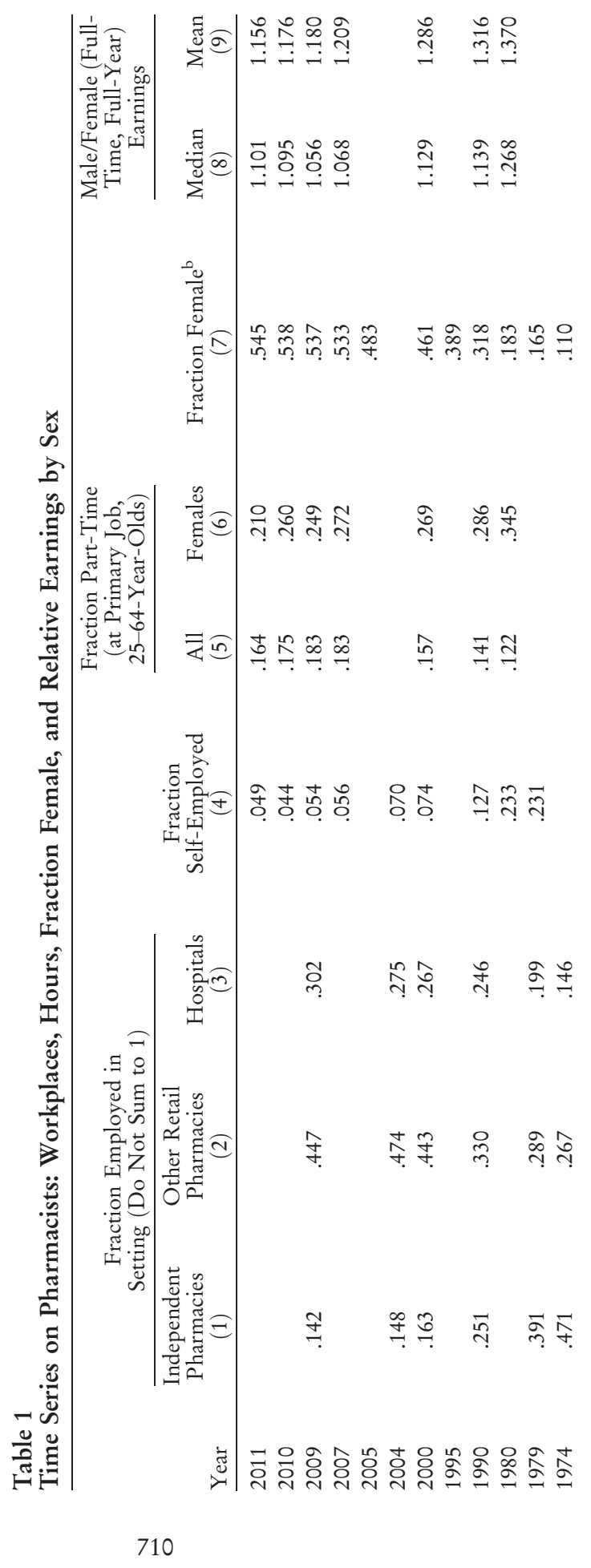

This content downloaded from 128.103.149.052 on July 22, 2016 09:12:20 AM All use subject to University of Chicago Press Terms and Conditions (http://www.journals.uchicago.edu/t-and-c). 


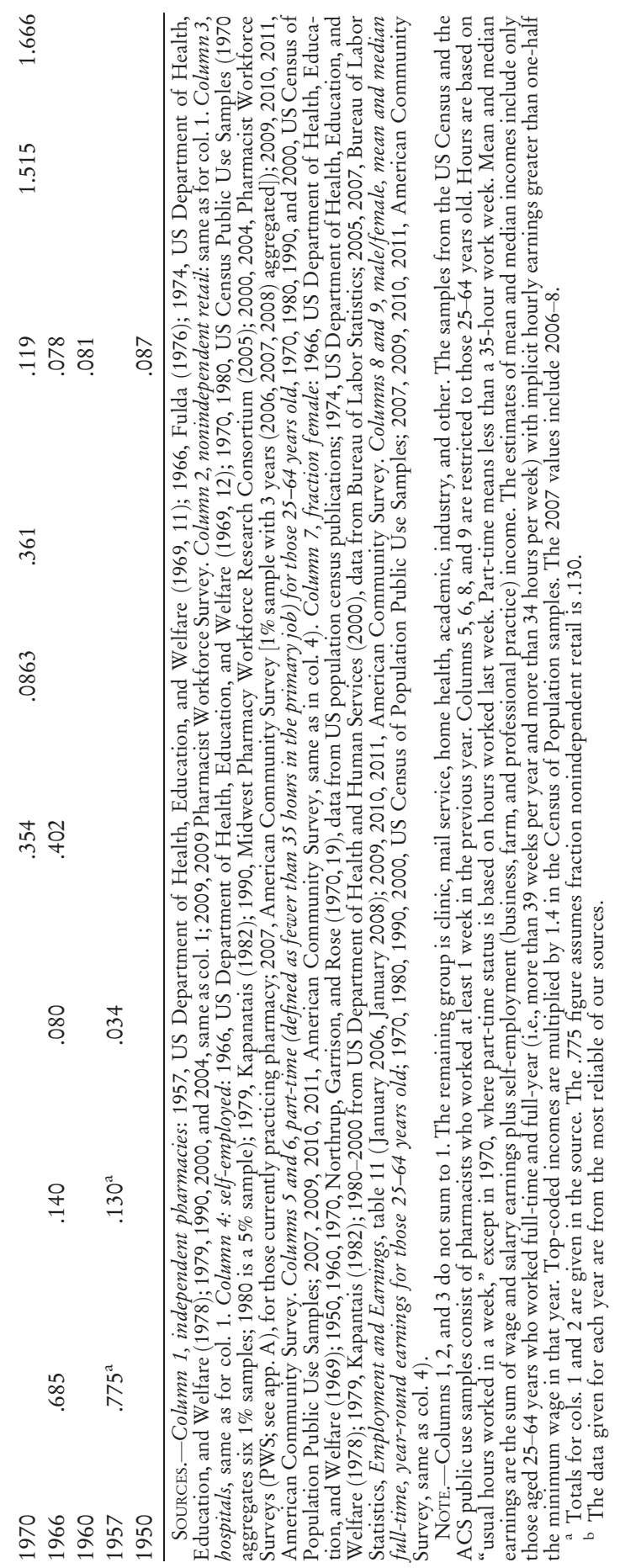


older than 40 years in the 2000 s, men were owners at four times the rate for women $(14 \%$ vs. $3.4 \%){ }^{6}$

The trend toward relatively fewer self-employed pharmacists also produced fewer pharmacists employed by independent pharmacies. The fraction employed by independents (as owners, partners, and employees) declined from more than $75 \%$ in the late 1950 s to $40 \%$ in 1980 to just $14 \%$ in 2009 (see table 1, col. 1, and fig. 2).

Increased pharmaceutical employment in large corporations, such as chain stores, supermarkets, and mass merchandisers, has been the main reason for these changes. Interestingly, the size of the prescription department, given by the number of pharmacists and technicians employed, differs little between the independents and the corporate retailers, although mass merchandisers and hospitals have larger prescription setups. About $45 \%$ of pharmacists in both independent practices and corporate retail stores report being the sole pharmacist on duty, and another $40 \%$ or so report being one of two pharmacists. ${ }^{7}$ The larger scale of the corporate retailers comes from aggregating all the pharmacies of a chain and also from the larger array of nonpharmacy items in each store.

The decline in ownership, the decrease of employment in independent pharmacies, and the rise of employee status stem largely from the first of the industry changes mentioned earlier involving the increased scale and scope of drug stores. Owners of independent pharmacies receive a premium to compensate them for added risk, responsibility, and time demands. The decrease in the fraction of owners means that relatively fewer pharmacists receive the ownership premium and that longer hours became less valuable. We will show that the annual earnings premium to ownership today is about $47 \log$ points but that the current ownership premium is primarily due to the greater hours worked by owners. Using US Census data, we show that self-employment for pharmacists commanded an earnings premium of 16 log points in 1970 but none today (given hours worked for both). ${ }^{8}$

The fraction of pharmacists who work part-time has greatly increased, from around $9 \%$ in 1970 to about $17 \%$ today (table 1, col. 5). But almost all of the change has been compositional, driven primarily by the rising share of women in the pharmacy profession (table 1, col. 7). Female pharmacists in past decades were employed part-time to a greater extent than they are today (table 1, col. 6). They often found part-time employment in independent pharmacies as assistants to the owner, and their earnings were considerably less than those of the owners, who were the residual claimants

\footnotetext{
${ }^{6}$ These data come from the Pharmacist Workforce Surveys (PWS), which we later present and use.

7 This is computed from PWS data.

${ }^{8}$ The self-employment measure in Census data is likely less accurate than the ownership measures in our surveys of active pharmacists for the 2000s.
} 


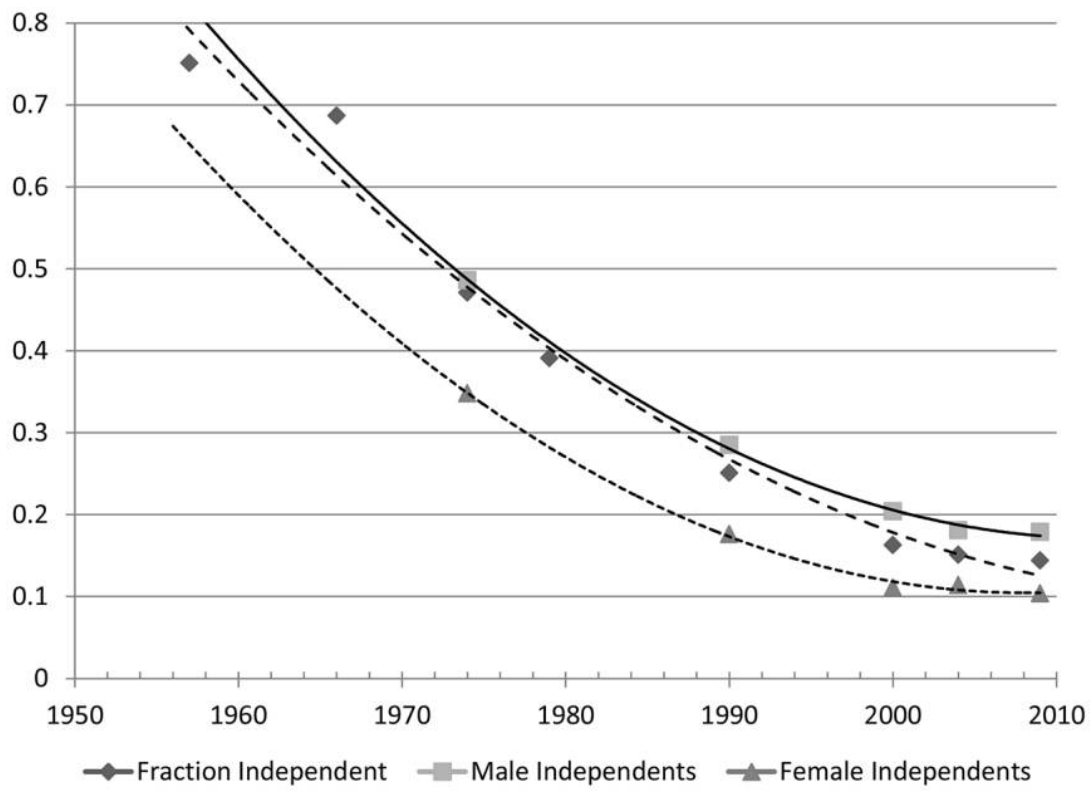

FIG. 2.-Fraction of pharmacists working in independent practices, by sex, 1957-2009. SOURCES: US Department of Health, Education, and Welfare (1969); Fulda (1976); US Department of Health, Education, and Welfare (1978); Kapantais (1982); US Department of Health and Human Services (2000); and Pharmacist Workforce Surveys for 2000, 2004, and 2009 (see app. A). NotE: A pharmacist working in an independent practice can be an owner or an employee. By "independent practice" we mean a unit or series of units for which one of the owners makes the majority of the decisions. Independent practices can have several stores, but they are not "chains" in the sense that they are not run by large corporations. The fraction in independent practice is obtained by taking the number in independent retail practice relative to all active pharmacists. The trend lines are quadratics.

(Henderson 2002). Changes in ownership and employee status are likely to have decreased the costs of temporal flexibility and therefore increased the ratio of female to male earnings, since women had a greater demand for the amenity.

\section{B. Pharmacist Training and Regulations}

Practicing pharmacy in the United States today involves a 6-year pharmacy course in a college or university resulting in a PharmD, practical experience, and licenses. 9 Pharmacy instruction was once based in

${ }^{9}$ A PharmD can be obtained after a BA or BS from a non-pharmacy school, but the program is generally another 4 years. The combined PharmD undergraduate and graduate programs are 6 years. 
medical colleges, but it shifted in the 1800 s to pharmacy schools. After the 1880s, pharmacy programs were established mainly within colleges and universities. Ever since 1932, the pharmacy curriculum has been specified by the American Council on Pharmaceutical Education (ACPE), which also accredits pharmacy colleges and programs. Program length is recommended by the American Association of Colleges of Pharmacy (AACP). ${ }^{10}$

In 1907 , a 2-year program was prescribed by the AACP, which was increased to 3 years in 1925 and then to 4 in 1932. In 1960, a 5-year BS program was recommended, and a 6-year combined $\mathrm{BS}$ and $\mathrm{PhD}$ program, known as the PharmD, was proposed in 1992. In 1997, the ACPE adopted accreditation standards requiring the PharmD, and the last 5-year BS for pharmacy graduates was granted to the class of 2005. In the Pharmacist Workforce Surveys (PWS) that we will use, $83 \%$ of those who received their first licenses after 2000 earned a PharmD, whereas 30\% did who received their first licenses in the 1990 s and just $15 \%$ did who were first licensed in the 1980s.

The demands for pharmaceuticals and pharmacists have greatly increased in recent years with an aging population, Medicare Part D drug coverage, and the expanded use of prescription drugs for a host of chronic diseases. As the demand for pharmacists has increased, the numbers of pharmacy schools and students per school have as well. From 2000 to 2010 , the number of schools granting a pharmacy degree increased by $22 \%$ (from 82 to 100 ) and total degrees increased by $58 \%$ (from 7,260 to $11,487) \cdot{ }^{11}$

\section{Pharmacy Today: Demographic Aspects and Earnings}

A. Pharmacist Workforce Surveys (PWS): 2000, 2004, and 2009

To better understand the pharmacy sector today, we use individual microdata from surveys devised by the Midwestern Pharmacy Research Consortium for the years 2000, 2004, and 2009 covering about 5,300 pharmacists with active licenses. ${ }^{12}$ The surveys were mailed in each of the years to a randomly chosen group of about 4,500 currently licensed pharmacists. Usable response rates were around $40 \%$ in each year, with quite

\footnotetext{
${ }^{10}$ It probably has been ever since the inception of the AACP in 1900. For a history of pharmacy, see Kremers, Sonnedecker, and Urdang (1986) and Henderson (2002).

${ }^{11}$ These data are from compilations by the AACP, http://www.aacp.org/about /Pages/Vitalstats.aspx. The total number of schools increased by $44 \%$ (from 82 to 118) because 18 had been established in the previous 5 years but were not yet granting degrees.

${ }_{12}$ Tabulations are in three reports (Midwest Pharmacy Research Consortium $2000,2005,2010)$.
} 
similar response rates by gender. ${ }^{13}$ Most of our analyses aggregate the data across years. The data set is termed the Pharmacist Workforce Survey and is described in appendix A.

Each of the surveys contains detailed economic information, including income from primary and other jobs, bonuses, overtime, hours, weeks, and job experience. Data on education includes postsecondary degrees in pharmacy and other fields. The dates and states of pharmacy licensing are included. Demographic variables include race, ethnicity, marital status, and numbers and ages of children. ${ }^{14}$ The three surveys are nearly identical, but the 2009 survey contains richer information on all job changes during the individual's career.

\section{B. Pharmacist Characteristics and Practice Settings}

The most important demographic change among pharmacists is the increased fraction female. Women were about $8 \%$ of all pharmacists in 1960 and are about $55 \%$ today (table 1, col. 7). The fraction female among pharmacy school graduates increased from $14 \%$ in the mid-1960s to about $65 \%$ today (see fig. 3 ).

Female pharmacists marry at about the same rate as male pharmacists, and they have about the same number of children. The fraction of female pharmacists without children by their forties is about $21 \%$, which is lower than for other female graduates of 4-year colleges in that age group. ${ }^{15}$ The fraction of pharmacists 25-44 years old who have ever married is somewhat greater for women than men (table 2). Although the fraction of women 25-44 years old without children is higher than for men, the fraction without children in their early forties is more similar ( 0.18 for men and 0.21 for women). It is likely that the main reason that female and male pharmacists have similar numbers of children is that pharmacy is enabling of family.

The PWS data for 2009 allow the computation of spells out of the workforce and the reason why employment was terminated. ${ }^{16}$ Even though

${ }^{13}$ The usable response rates ranged from $34 \%$ in 2004 to $43 \%$ in 2000 to $52 \%$ in 2009. There are no statistically significant differences in response rates by gender in the PWS in 2000 and 2004, the 2 years for which the survey documentation provides such analyses (Midwest Pharmacy Research Consortium 2000, 2005, 2010).

${ }^{14}$ The 2009 survey includes only children living at home.

${ }^{15}$ Among all US BA women 40-44 years old in 2008, 22.8\% never had children (from CPS; see http://www.census.gov/prod/2010pubs/p20-563.pdf). Pharmacy survey data give $21.0 \%$ excluding 2009 and 20.2\% including 2009 (for currently employed pharmacists). The CPS data refer to biological children; the pharmacy surveys could include adopted and step-children.

${ }^{16}$ Respondents were asked to record the start and end dates of all employments since obtaining their pharmacy license and to include periods of nonemploy- 


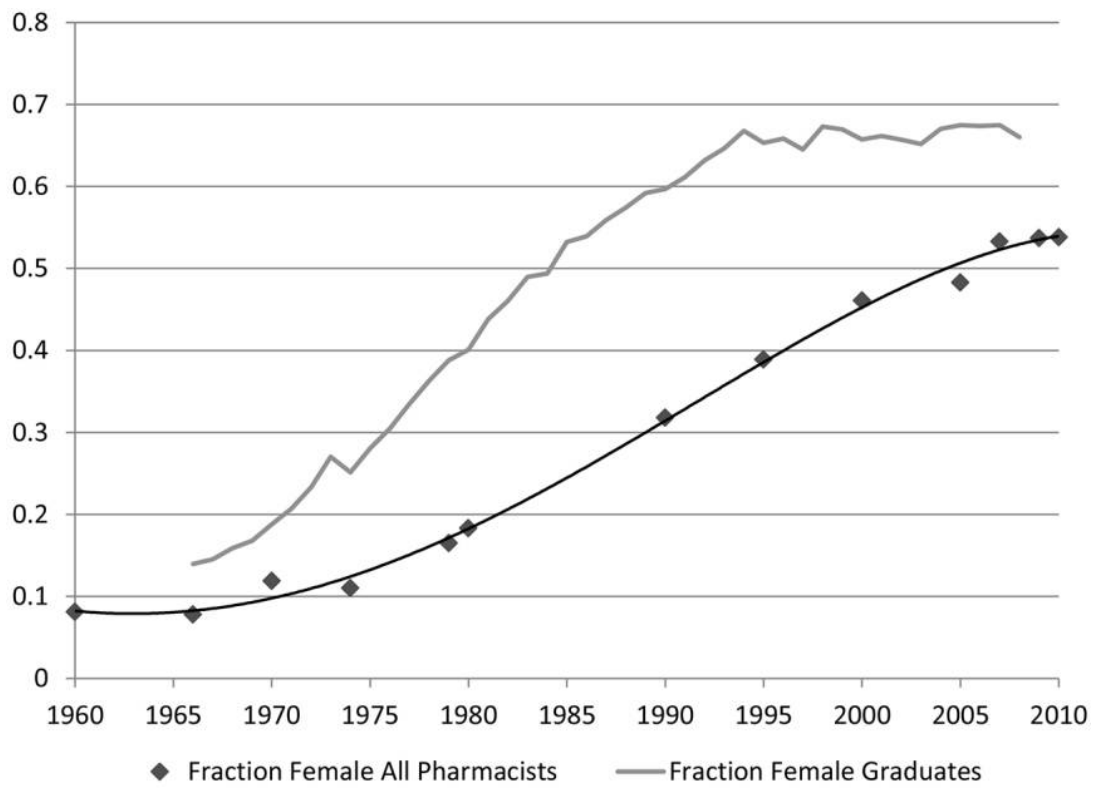

FIG. 3.-Fraction female among all pharmacists and pharmacy graduates. SoURCE: Fraction female among pharmacists for 1960-2010 from table 1, column 7. Fraction female among graduates of pharmacy programs, US Department of Education, Digest (various years). NOTE: Graduates of pharmacy programs include all who have attained a first professional degree. The first professional pharmacy degree changed over the period; see text. Trend line for the fraction female pharmacists is a fourth-degree polynomial.

more female than male pharmacists experienced a nonwork spell, the average spell was fairly brief. Among those with active pharmacy licenses, 13.9\% of women (5.1\% of men) ever had a spell out of the workforce. The median cumulative time out for those of all ages who had at least one nonwork spell was 2.4 years for women and 2.1 years for men. The means were 4.4 and 4.8 years for women and men, respectively. Although these data are based on small samples because of the low fraction who ever took time out, they are suggestive that female pharmacists do not take much time out, and, conditional on taking out time, they take about the same amount as male pharmacists.

The fact that the PWS data are limited to those with active pharmacy licenses could bias the data on labor force persistence for female pharmacists, but information from the American Community Surveys (ACS) on

ment. They were also asked the reasons employment was terminated if the individual was not in the labor force during a spell. 
Table 2

Characteristics of Pharmacists and Pharmacist Workplaces, 2000-2009

\begin{tabular}{|c|c|c|}
\hline & Males & Females \\
\hline \multicolumn{3}{|l|}{ Setting type, fraction (sums to 1 ): } \\
\hline Independent & .190 & .112 \\
\hline Chain & .276 & .253 \\
\hline Mass merchandiser & .0596 & .0603 \\
\hline Supermarket & .102 & .0987 \\
\hline Hospital & .242 & .313 \\
\hline Other patient care & .105 & .124 \\
\hline Other & .0260 & .0384 \\
\hline \multicolumn{3}{|l|}{ Position, fraction (sums to 1 ): } \\
\hline Employee & .543 & .738 \\
\hline Manager & .337 & .235 \\
\hline Owner & .120 & .0269 \\
\hline \multicolumn{3}{|l|}{ Demographics (for 25-44-year-olds): } \\
\hline Ever-married, fraction & .813 & .825 \\
\hline No. of children ${ }^{a}$ & 1.343 & 1.213 \\
\hline No. of children conditional on having one & 2.02 & 1.99 \\
\hline No children, fraction & .333 & .392 \\
\hline No children, $40-44$ years, fraction ${ }^{a}$ & .180 & .210 \\
\hline
\end{tabular}

SOURCE.-Pharmacist Workforce Surveys (2000, 2004, 2009). See app. A.

NoTE.-The merged sample from the 3 years is used, and data are tabulated for those with active pharmacy licenses who are currently employed as pharmacists. Owner = owner, partner, executive. Gender differences in setting and position are not much affected by age differences between men and women pharmacists. "Chains" are retail pharmacies owned by corporations.

"Independents" that have several stores are not considered chains.

${ }^{a}$ For the 2000 and 2004 surveys only. See app. A.

field of degree suggests otherwise. Among women 25-64 years old with at least a bachelor's degree in the 2009, 2010, and 2011 ACS, those with a degree in pharmacy had a participation rate of $86.0 \%$ as compared with $81.3 \%$ for other college graduate women. ${ }^{17}$ Among college graduate women aged 35-39 years, the participation gap favoring pharmacy graduates over other fields was even greater ( $88.3 \%$ vs. $82.1 \%)$. An unusually high fraction of women with pharmacy degrees persist in the labor force. ${ }^{18}$ Rather than taking time off or dropping out, they work part-time.

Practice settings today are fairly similar between men and women, with the largest differences that men are found more in independent practice, largely because they are disproportionately the owners, and women are

${ }^{17}$ A regression of an indicator for labor force participation on an indicator for a bachelor's degree in pharmacy yields a 4 percentage point gap relative to other college-graduate women aged 25-64 (a coefficient of 0.040 with a standard error of 0.0058 ) conditioning on a full set of single-year age dummies and year dummies in the pooled 2009-11 ACS samples.

${ }^{18}$ See Knapp et al. (1992) on pharmacy degree holders in any employment. 
found more in hospital settings (table 2). Men are more likely than are women to be managers.

\section{Earnings Levels, Change, and Dispersion}

Not only are female pharmacist earnings relatively high compared with male pharmacist earnings, pharmacist earnings are currently high for both men and women compared with all comparable professions. For fulltime, year-round workers in only seven other detailed occupations does the median male worker earn more and in only two others does the median female worker earn more. ${ }^{19}$

Pharmacist earnings have risen relative to most other health-care professionals ever since the late $1990 s .{ }^{20}$ From 1999 to 2013, pharmacist median annual earnings increased relative to 39 out of the 40 health-care professions (that are not top-coded in both years) listed in the Bureau of Labor Statistics Occupational Employment Statistics (BLS-OES). ${ }^{21}$ In 1999, pharmacist earnings were 1.15 times chiropractor earnings, for example, but were 1.83 times that in 2013. Pharmacist earnings were 0.87 of optometrist earnings in 1999, but they were 1.18 times higher in 2013, and pharmacist earnings rose relative to the four physician specialties in the OES (that do not have top-coded median annual earnings), including internists, pediatricians, and psychiatrists.

Pharmacy is an egalitarian occupation, especially given its high average earnings. According to the May 2011 BLS-OES, pharmacists have the lowest wage dispersion of all occupations with earnings exceeding $\$ 60,000$ per year (or more than $\$ 40$ per hour), where wage dispersion is measured either by the ratio of earnings at the 90 th percentile relative to that at the 10 th percentile or similarly for the 75 th and 25 th percentiles. ${ }^{22}$ In fact the level of wage dispersion for pharmacists would be twice the actual level if one used data on the 800 or so occupations in the OES and predicted wage dispersion on the basis of average earnings. Pharmacist earnings have the lowest dispersion among any of the health-care occupations.

${ }^{19}$ The two higher paid occupations for women are nurse anesthetists and physicians (source is the 2010 ACS).

${ }^{20}$ Census and ACS data from 1950 to 2010 show that, relative to physicians, pharmacist earnings first declined and then increased. The increase from 1990 to the present has brought the ratio of their median earnings for males back to approximately its level in 1950 (0.57).

${ }^{21} \mathrm{http} / / / \mathrm{www}$. bls.gov/oes/current/oes_nat.htm was used for 2013 and http:// www.bls.gov/oes/1999/oes_nat.htm was used for 1999. Only radiology therapists, a lower-paying health-care occupation, had earnings that rose a bit faster from 1999 to 2013.

${ }^{22}$ Tabulations from the National Cross-Industry Estimates of the May 2011 Occupational Employment and Wage Estimates are available at http://www.bls .gov/oes/2011/may/oes_nat.htm. 


\section{Earnings by Sex, Hours, and Compensating Differentials}

\section{A. Gender Earnings Gap in Pharmacy}

Another aspect of the egalitarian nature of pharmacy is its low gender wage gap. To understand the factors that make this occupation different from many others, we examine the gender gap for currently practicing licensed pharmacists using the Pharmacist Workplace Surveys for 2000, 2004, and 2009. ${ }^{23}$ We estimate a standard log earnings equation with $(\log )$ hours, (log) weeks, dummies for position (owner, manager, employee) and sector (chain, independents, hospital, other), education (graduate degrees), age as a quadratic, and whether the person has a child.

The raw annual earnings gender gap given in table 3, column 1, is $27 \log$ points, using data pooled across the 3 years. The addition of log hours per week and log weeks worked to the log annual earnings regression reduces the gender earnings gap from 27 to 7.6 log points (col. 2), demonstrating that the gender gap in annual earnings for pharmacists largely reflects differences in hours worked. The specification in column 2 may understate the role of hours worked with downward-biased estimates on the log hours per week and log weeks coefficients because of measurement error in self-reports of hours and weeks worked. The specification in column 3 addresses this issue by restricting the coefficients on log hours and log weeks in column 2 to be one. In that specification, the gender gap in log hourly earnings is just 4.7 log points.

The shorter work week of female pharmacists is the largest single component of the gender earnings gap. Female pharmacists in our earnings sample work 6.6 fewer hours per week than male pharmacists (36.6 hours for women per week and 43.2 for men) for a 20 log point gap, and they work 0.7 fewer weeks per year ( 47.5 weeks for women and 48.2 for men) for a $2 \log$ point gap. Thus, the overall 27 log point annual gender earnings gap consists of $20 \log$ points from gender differences in hours per week and $2 \log$ points from differences in weeks worked per year. The remaining $4.7 \log$ points constitute the hourly wage gap.

We next examine the gender earnings gap conditional on covariates to control for differences in educational attainment, race and ethnicity, potential labor market experience (through a quadratic in age), ownership of a pharmacy and managerial responsibilities, and sector of employment (retail chain, independent pharmacy, hospital, or other setting) in table 3 , columns 4-6. The addition of these covariates modestly reduces the gender annual earnings gap from $27 \log$ points to $23.5 \log$ points in the specification without controlling for hours and weeks worked (col. 4), largely

${ }^{23}$ Related analyses of the gender earnings gap in other professions include Wood, Corcoran, and Courant (1993) for lawyers; Bertrand, Goldin, and Katz (2010) for MBAs; and Sasser (2005) for physicians. 


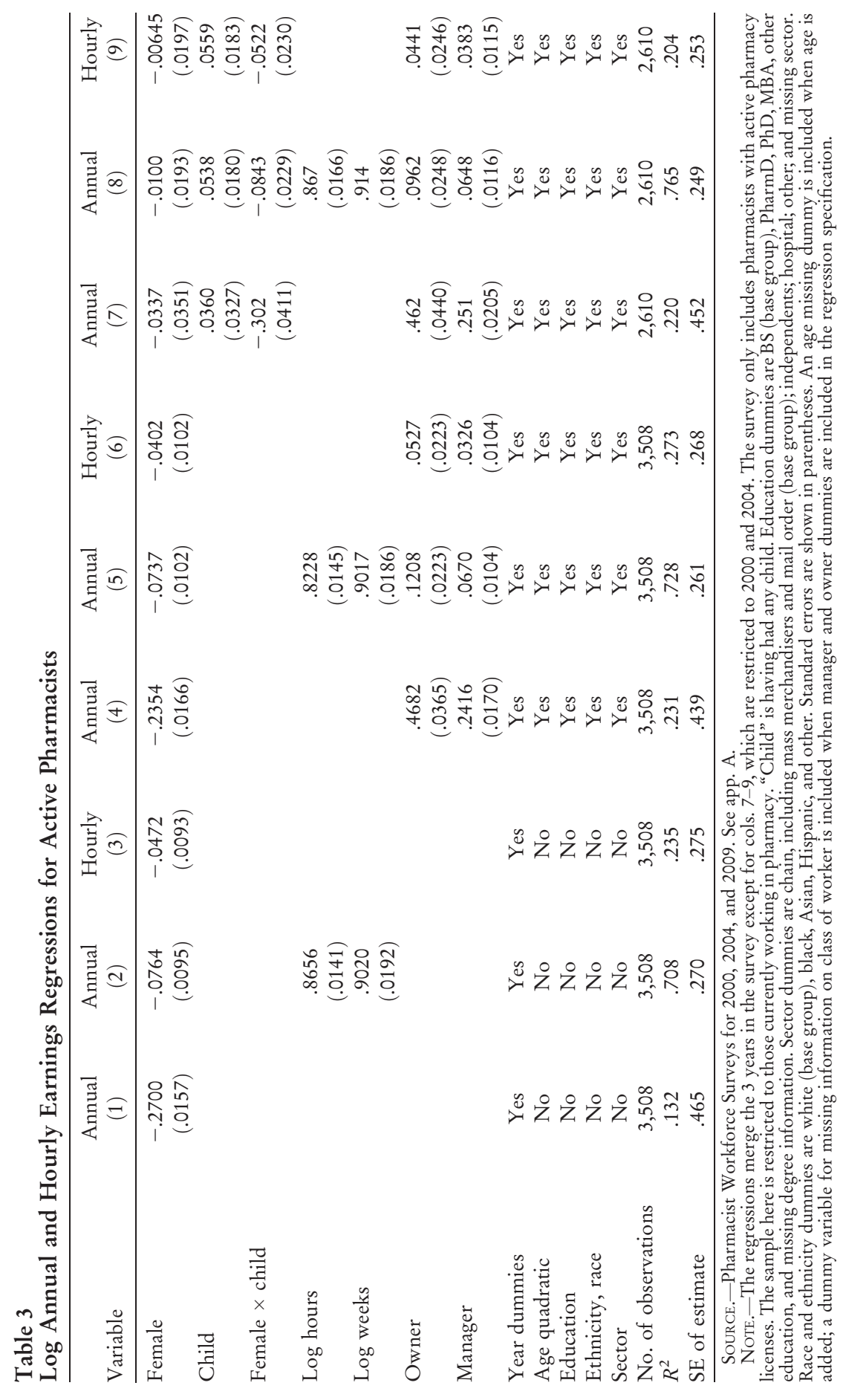

This content downloaded from 128.103.149.052 on July 22, 2016 09:12:20 AM 
because women are more likely to be employees and less likely to be owners or managers (see table 2). A substantial annual earnings premium is apparent for owners (47 log points) and managers ( $24 \log$ points) when not controlling for hours. The addition of hours and weeks (col. 5) reduces the owner and manager premium substantially, as does the estimation using hourly earnings. In the hourly estimation, owners earn $5 \log$ points more than employees and managers just 3 log points more.

Differences in age and labor market experience between men and women play no role in the estimated gender earnings gap since there appears to be little labor market return to experience. There is a relatively flat age-earnings profile for licensed pharmacists in the PWS samples. The additional covariates only slightly reduce the gender earnings gap once one controls for hours and weeks (compare cols. 5 and 6 with cols. 2 and 3 ).

Substantial gender differences in pharmacists' hours worked and in earnings are only apparent for those with children. ${ }^{24}$ The gender earnings gap for those without children is $3 \log$ points even without controlling for hours, but the gender earnings gap is $33 \log$ points for those with children (col. 7). In specifications controlling for hours and weeks, the gender earnings gap for those without children is only 1 log point (cols. 8 and 9). Differences in hours worked by sex substantially explain the much larger gender earnings gap for those with children.

Our findings from the PWS are similar to those we find using the ACS for 2009-11. The samples may be somewhat different because the former refers to currently employed pharmacists with active licenses, whereas the latter is for individuals who list themselves as employed pharmacists. Using the data from the ACS, we find a gender earnings gap of about $25 \mathrm{log}$ points for annual earnings in models controlling for a quadratic in age and dummy variables for educational attainment, race and ethnicity, broad sector, and year. Further controls for hours and weeks reduce the gender gap to 7 log points. ${ }^{25}$ The results from the rich data in the PWS can be largely replicated using a pharmacy subsample in a nationally representative survey.

The gender earnings gap for pharmacists principally reflects differences in hours worked by male and female pharmacists. These differences in hours for women are strongly related to the presence of children. Owners

\footnotetext{
${ }^{24}$ Regressions in table 3, cols. 7-9 are run on only the 2000 and 2004 samples because only the 2009 survey asked about children living at home. Results for cols. 1-6 run over the restricted sample produce similar gender differences to those given in table 3 for the full sample.

${ }^{25}$ The regression sample includes all 8,297 individuals in the 2009, 2010, and 2011 ACS PUMS listing pharmacy as their current occupation with positive weeks worked in the past year and non-outlier earnings (implied hourly earnings between $\$ 6$ and $\$ 300$ an hour).
} 
and managers earn more largely because they work more hours. The number of hours worked is decisive for almost all differences in pharmacy earnings.

\section{B. Pharmacist Hours and Part-Time Employment}

Although male and female pharmacists have similar hours of work at the start of their professional lives, hours for women soon decline (see fig. 4, $A$ ). Total hours for men from their early thirties average around 45 per week, whereas they are about 37 for women. ${ }^{26}$ Hours of work for pharmacists are relatively low given the income ranking of the profession.

Among women who have children of any age, hours of work in the primary job are around 6-10 hours lower than for women without children until the women are in their fifties (see fig. 4, B). Although hours are lower for women with children than for those without, women without children work fewer hours than all men, suggesting that female pharmacists work fewer hours for reasons other than taking care of their children. $^{27}$

Part-time work (fewer than 35 hours per week) in all jobs worked by currently licensed pharmacists is about $6 \%$ for males and $9 \%$ for females at the start of their careers (see fig. $4, C$ ). ${ }^{28}$ The fraction part-time falls to about $5 \%$ for males and rises to around $36 \%$ for females. For women with children, the fraction working part-time at all jobs remains above $40 \%$ until they are in their late forties, showing that those who work part-time when their children are young continue to do so later in life.

It will be recalled, from table 1, that the fraction of women working parttime has always been high in pharmacy, and it has probably decreased somewhat over time. The barrier to female employment in pharmacy in the past was that the earnings penalty to working part-time was large, not that part-time work was difficult to find. The part-time and lower-hours penalty dropped when most pharmacists became employees and few were owners.

The ratio of male to female (mean) earnings for full-time, year-round pharmacists in 1970 was 1.67 (see table 1, col. 9). Women gained on men over time, and by 2011 the ratio had fallen to 1.16 . The ratio for median earnings of male to female full-time, year-round pharmacists was 1.52 in 1970 , but it was 1.10 in 2011 . The change from 1970 to the present is fairly continuous. Including the part-time and part-year group would increase

${ }^{26}$ Total hours in pharmacy employment include time spent working in the primary job plus overtime in that position and hours in all secondary positions.

${ }^{27}$ The sample of women without children at older ages is small.

${ }^{28}$ The fraction working part-time across all employments is lower than for the primary job only. 
A. Hours of work (in all jobs) for all pharmacy positions, by age

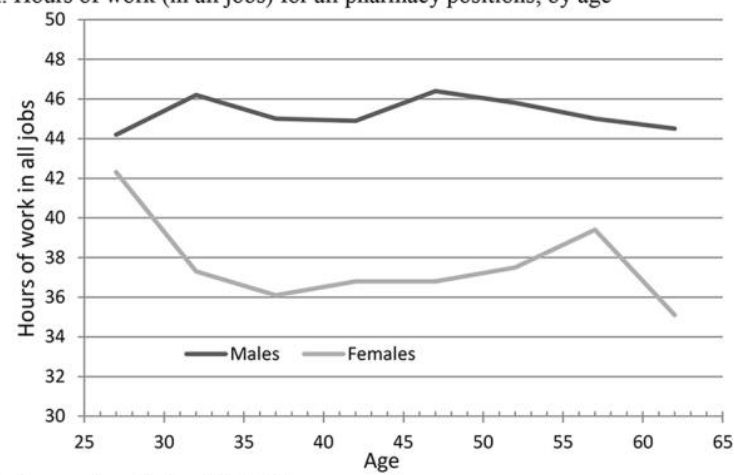

B. Hours of work (in all jobs) for women by age

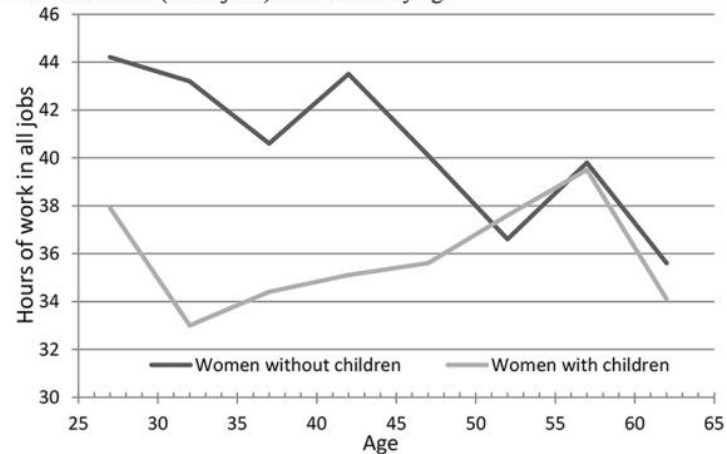

C. Fraction part-time (including all employments) by age

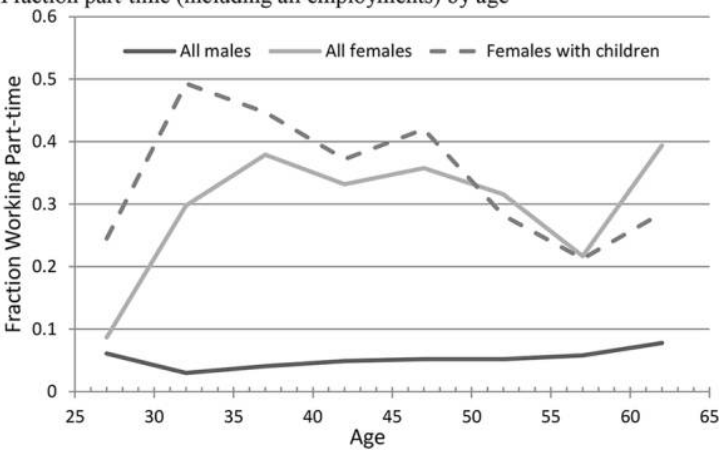

Fig. 4.- - Hours of work and part-time employment for male and female pharmacists. Source: Pharmacist Workforce Surveys. See appendix A. Note: Figure A and the "all" lines for figure B are for all years (2000, 2004, and 2009). Figure B, "females with children," and figure C are only for the years 2000 and 2004 because of the different reporting of children in 2009. All figures refer to currently employed individuals with active pharmacy licenses and positions as pharmacists. Total hours include those on the primary pharmacy job, overtime on the primary job, and hours in secondary and other pharmacy positions. Part-time is defined as working fewer than 35 hours in all employments. 
the female disadvantage at the start relative to the end of the period and produce a larger narrowing of the gender earnings gap. ${ }^{29}$

One factor that enables pharmacy to have a low earnings gender gap today is that its remuneration is fairly linear with respect to hours and weeks. In contrast, many lawyers and those employed in the corporate and financial sectors are rewarded considerably more if they work long hours and their earnings are nonlinear (convex) with respect to hours worked (Bertrand et al. 2010; Goldin and Katz 2011; Goldin 2014).

The changes in the organization of the pharmacy industry that reduced the importance of independent pharmacies and ownership and increased employee status may have enabled lower hours for pharmacists, but, according to some in the business, they have produced increased workloads per hour and worker stress. ${ }^{30}$ The PWS asked questions on workloads, including prescriptions filled per day or week and the perceived work level. For both males and females, workloads, as measured by prescriptions filled, are lower for independents and supermarkets and highest for chains, mass merchandisers, and hospitals. The workload at the independents is around $15 \%-40 \%$ higher than at the chains. ${ }^{31}$ Workloads and the perception of the load do not differ much by gender. Job satisfaction is highest for those at the independents and lowest at the mass merchandisers. About two-thirds of pharmacists in the chains are reasonably content, and female pharmacists are generally more content than are male pharmacists in the same work setting.

\section{Hourly Wage Penalty to Part-Time Employment}

We have shown that pharmacy is a fairly egalitarian occupation, with only modest hourly wage premiums for ownership and managerial responsibilities. We now examine the hourly wage penalty to working part-time (fewer than 35 hours per week) for pharmacists. We limit the PWS sample to those directly reporting hourly earnings and weekly hours to avoid measurement error (division bias) problems. ${ }^{32}$

The 2000 and 2004 PWS allowed respondents to report earnings in their preferred manner. The majority of the respondents $(59 \%$ overall: $56 \%$ of

${ }^{29}$ In fact, the ratio for median (mean) annual earnings of all male to all female pharmacists with positive earnings, including the part-time and part-year workers, fell from 2.07 (2.04) in 1970 to 1.11 (1.23) in 2011 using the 1970 Census and 2011 ACS public use samples.

${ }^{30}$ See, e.g., Miller (2012).

${ }^{31}$ Prescriptions filled per day are available for 2004 only. Active pharmacist males working for a chain filled 165 and females filled 159. Those in supermarkets filled 119 for both males and females. Nonowner men in independents filled 125 and nonowner women filled 138.

32 These problems arise from using constructed hourly earnings from retrospective reports of annual earnings, hours, and weeks worked. 
males and $63 \%$ of females) directly reported hourly earnings. Column 1 of table 4 repeats the $\log$ (hourly earnings) regression specification in column 6 of table 3 adding a part-time work indicator variable and restricting the sample only to those reporting hourly earnings. The gender hourly earnings gap narrows to $2.5 \mathrm{log}$ points for this sample, and the part-time hourly earnings penalty is nonexistent. ${ }^{33}$ The part-time hourly earnings penalty is also essentially zero when looking only at female pharmacists in the 2000 and 2004 PWS (col. 2). More generally (in unreported regressions), we find no significant systematic relationship between hourly earnings and weekly hours for pharmacists who directly reported hourly earnings.

Is pharmacy an occupation with a low penalty for part-time work in comparison with other occupations? The question is addressed here using the point-in-time information on hourly wages for workers paid by the hour, weekly earnings for all wage and salary workers, and usual weekly hours in the large nationally representative Current Population Survey Merged Outgoing Rotation Group (CPS MORG) samples for 2005-13.

We first explore the gender hourly earnings gap and part-time wage penalty for pharmacists and other college graduate wage and salary workers. Because most college graduates are salaried workers and do not report an hourly wage in the CPS, we use the log of constructed hourly earnings, that is $\log$ (weekly earnings/usual weekly hours), as the dependent variable in table 4 , columns $3-5$, to compare pharmacists with all other college graduates.

The estimates in column 3 indicate a 26 log point part-time work penalty and a $19 \log$ point gender hourly earnings gap for nonpharmacist college graduates and a much smaller part-time penalty ( 6 log points) and gender earnings gap (9 log points) for pharmacists. The addition of a full set of detailed (three-digit) occupation dummies in column 4 reduces the nonpharmacist part-time wage penalty to $14 \log$ points and the gender earnings gap to $13 \log$ points. ${ }^{34}$ But the substantially smaller part-time work and gender hourly earnings penalties for pharmacists remain intact. A parttime work penalty is nonexistent for female pharmacists (see col. 5) but is almost $21 \log$ points for other female college graduates. Similarly, a much smaller part-time work penalty and gender hourly earnings gap exists for pharmacists than for other occupations, and no part-time wage deficit for female pharmacists is found when we use the log (hourly wage) based on direct reports for current hourly wages for workers paid by the hour in the CPS (see cols. 6-8).

${ }^{33}$ There is enough precision to rule out even a $2 \log$ point wage penalty for parttime work.

${ }^{34}$ This specification has greater comparability to the within-occupation analysis for pharmacists in table 4, col. 1 . 


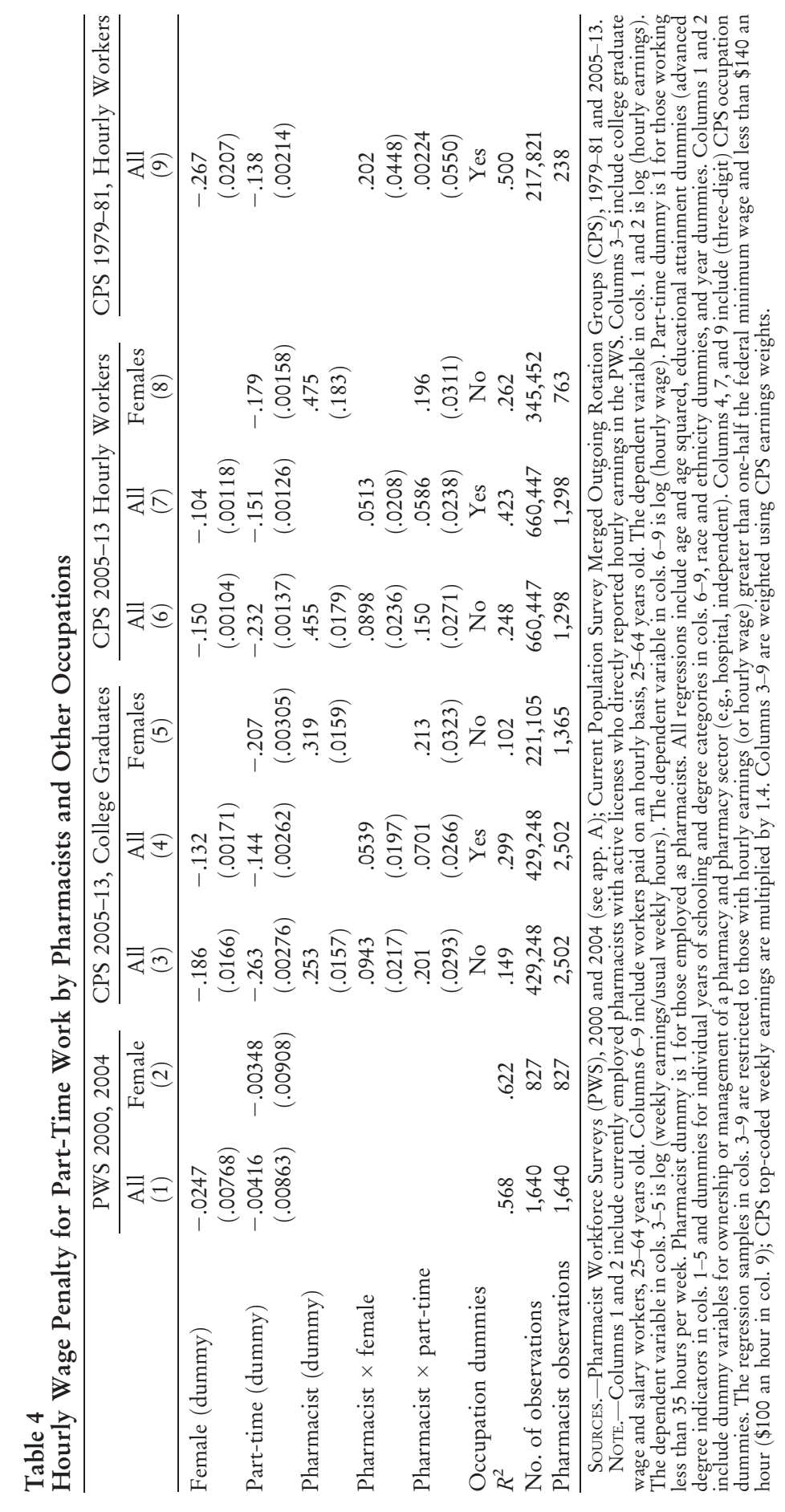

This content downloaded from 128.103.149.052 on July 22, 2016 09:12:20 AM All use subject to University of Chicago Press Terms and Conditions (http://www.journals.uchicago.edu/t-and-c). 
The part-time wage penalty for pharmacists, as we have shown, is small in recent data. We now show that it has declined since 1980, using the earliest CPS MORG samples for 1979, 1980, and 1981. In column 9 of table 4 , in a regression analogous to that of column 7 with a full set of occupation dummies, we find no significant difference in the part-time wage penalty for nonpharmacist hourly workers (14 log points) and hourly pharmacists (14 log points) around 1980. We should note that one cannot rule out a modestly lower part-time wage penalty for pharmacists in 1980 given the modest sample size of hourly pharmacists and imprecision of the estimates. ${ }^{35}$ We similarly find no significant difference in the part-time wage penalty for nonpharmacist college graduates (10 log points) and pharmacists (11 log points), using the 1979-81 CPS data in a specification analogous to column 4 of table 4.

Thus, the part-time wage penalty for pharmacists shrunk and essentially disappeared for female pharmacists during the past 3 decades. During that time period, pharmacy employees became better substitutes for each other with improved information technology and more standardized products, whereas a substantial part-time wage penalty has persisted for comparable workers.

\section{Changing Hours, Self-Employment, and Family among Pharmacists, 1970-2010}

We showed in table 1 that the gender earnings gap among (full-time, full-year) pharmacists decreased considerably since the late 1960s, along with the fraction self-employed and working in independent practice. The implication of our explanation for these changes is that the premium to working longer hours should have greatly decreased over the ensuing decades. Whereas longer hours in 1970 should have increased earnings by a lot, longer hours today should not be as remunerative. In addition, since women with children, particularly younger children, would have a greater demand for temporal flexibility, the penalty to having children should have been greater in the past. We now demonstrate these time trends in table 5 using the 1970 US Census and the 2009-11 American Community Surveys for all employed pharmacists (not just those working full-time and fullyear). ${ }^{36}$

The pharmacy profession looked quite different in 1970 than it does today. Women comprised $11 \%$ of pharmacists in 1970 as compared with $56 \%$ in 2010 , among those $25-64$ years old with at least a bachelor's

${ }^{35}$ The low gender hourly earnings gap in pharmacy for hourly (as well as for wage and salary) workers in 1979-81 partially reflects the large share of highearning male pharmacists who were self-employed and do not report earnings the CPS Outgoing Rotation Group samples.

${ }^{36}$ We focus on pharmacists 25-64 years old with at least a bachelor's degree for comparability across the long time span covered and to avoid retirement issues. 


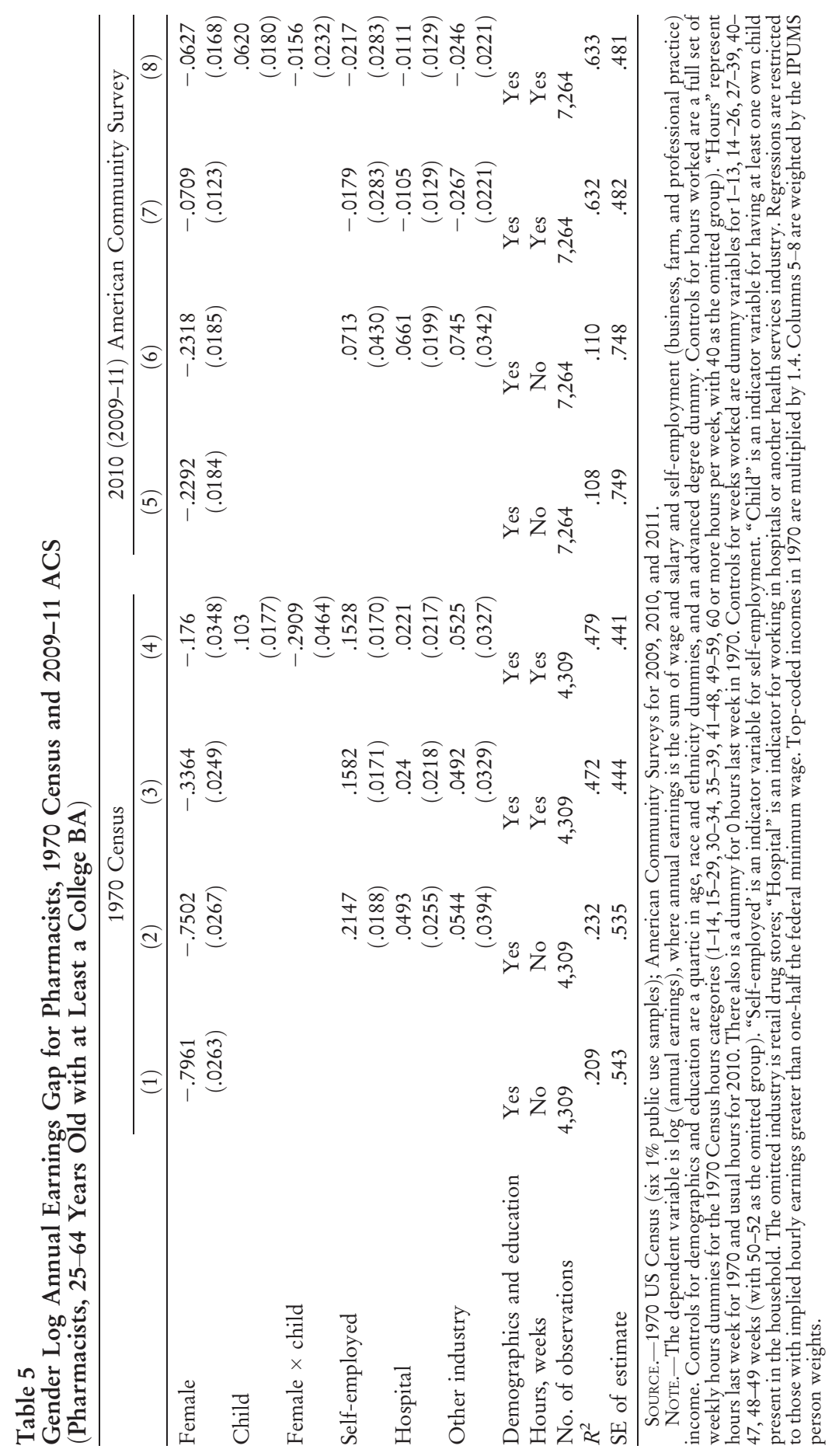

This content downloaded from 128.103.149.052 on July 22, 2016 09:12:20 AM All use subject to University of Chicago Press Terms and Conditions (http://www.journals.uchicago.edu/t-and-c). 
degree. One-third of pharmacists were self-employed in 1970, and less than $5 \%$ were in 2010 . And over $82 \%$ of pharmacists worked in retail stores in 1970 versus $61 \%$ in 2010 . The difference in self-employment for male and female pharmacists was large in 1970 (36.4\% for males vs. $7.7 \%$ for females) and modest in 2010 (7.7\% for males vs. $2.2 \%$ for females). In 1970 , male pharmacists worked about 10 hours more per week than did female pharmacists (45.6 vs. 35.7 hours), but they worked just 4 hours more in 2010 (41.6 vs. 37.3 mean usual weekly hours). ${ }^{37}$

The gap in annual earnings between male and female pharmacists in 1970 was a whopping $80 \log$ points (table 5, col. 1), controlling for basic demographics and educational attainment, and 75 log points (col. 2), when differences in sector and self-employment are added. The gender earnings gap falls to $34 \log$ points when hours and weeks are added (col. 3). The gap was much larger for mothers (47 log points relative to fathers) than for women without children (18 log points relative to men without children) in 1970 (col. 4). Note, as well, that the self-employed in 1970 earned about $15 \log$ points more than other pharmacists even conditioning on hours worked.

These results change radically in 2010, reflecting the much smaller gender differences in hours worked and lower returns to long hours and self-employment. The basic annual gender earnings gap is much smaller, only $23 \log$ points (col. 5), and the addition of hours and weeks yields just a 7 log point gap (col. 7). Furthermore, once hours are included, the presence of children for a woman no longer significantly expands the gender earnings gap (col. 8). In addition, the self-employed earn no more than other pharmacists once hours worked is included.

In 1970, a female pharmacist with a child earned $46 \log$ points less than a male pharmacist with a child (and $37 \log$ points less than a male pharmacist without a child) even with hours, sector, and self-employment status held constant. But in 2010, a female pharmacist with a child earned only $8 \mathrm{log}$ points less than a male pharmacist with a child (and had almost identical earnings to a male pharmacist without a child) given hours, sector, and self-employment status.

\section{E. Earnings and Gender Pay Gaps among Pharmacist and Other College Graduates}

We now look at the earnings premium to being a pharmacist or having a pharmacy degree relative to other college graduates using the large and

37 The 1970 Census only provides categorical information on hours worked last week and does not have information on usual weekly hours for the previous calendar year. The 1980 Census has continuous measures of both hours worked last week and usual weekly hours last year. We impute usual weekly hours for the 1970 Census using the mean usual weekly hours in each discrete category for hours worked last week from the 1980 Census $5 \%$ public use sample. 
nationally representative 2009, 2010, and 2011 ACS public use samples. The 2009-11 ACS samples provide information on the detailed field of undergraduate degree for all individuals with at least a bachelor's degree. The ACS samples are well suited for examining earnings differences among full-time, year-round workers since information is given on annual earnings and usual weekly hours in the past year. The ACS, however, has only categorical information on weeks worked in the previous year.

The log (annual earnings) regression for full-time, full-year college graduates, ages 25-64, in column 1 of table 6 shows a substantial earning premium of $25 \log$ points for male pharmacy bachelor's degree holders in comparison with other college graduates (conditional on potential experience, higher degrees, race and ethnicity). The premium for female pharmacy bachelors is $36 \log$ points. ${ }^{38}$ These results imply an 11.5 log point smaller conditional mean gender earnings gap for pharmacy bachelors relative to other college graduates (17 vs. 28 log points). The lower dispersion in earnings for pharmacists means the earnings premium for pharmacy bachelors is even larger and the gender earnings gap smaller when examining conditional median earnings differences in a median (quantile) regression. The gender earnings gap remains significantly smaller for pharmacy bachelors (by 7 log points) than other college graduates even for within field-of-degree comparisons (see col. 3).

The high earnings premium for pharmacy degree holders is substantially driven by individuals employed as pharmacists, particularly for women. The specification in column 4 shows that the earnings premium for pharmacy bachelors is lower for those not working as pharmacists and that the earnings premium for working as a pharmacist is large, especially for women (18 log points for men and 39 for women).

The specifications in columns 5-7 of table 6 explore the earnings premium and gender earnings gap for pharmacists relative to other college graduates in specifications that do not include field of degree controls. The gender earnings gap is much smaller for pharmacists than for other college graduates. Even using within-occupation comparisons, the gap remains $18 \log$ points for nonpharmacists and less than $10 \log$ points for pharmacists (col. 7).

The bottom line from our exploration of earnings by field of degree and occupation in the 2009-11 ACS is that male and female pharmacy degree holders earn substantially more than other college graduates with

${ }^{38}$ Altonji, Blom, and Meghir (2012) similarly find that pharmacy bachelor's degree holders have the sixth-highest earnings for men and the fifth-highest earnings for women out of 171 detailed field-of-degree categories for full-time, full-year college graduates, 23-59 years old in specifications controlling for potential experience, higher-degree dummies, and race in the 2009 ACS. And female pharmacy degree holders have the highest earnings for any degree field with a significant female presence. 


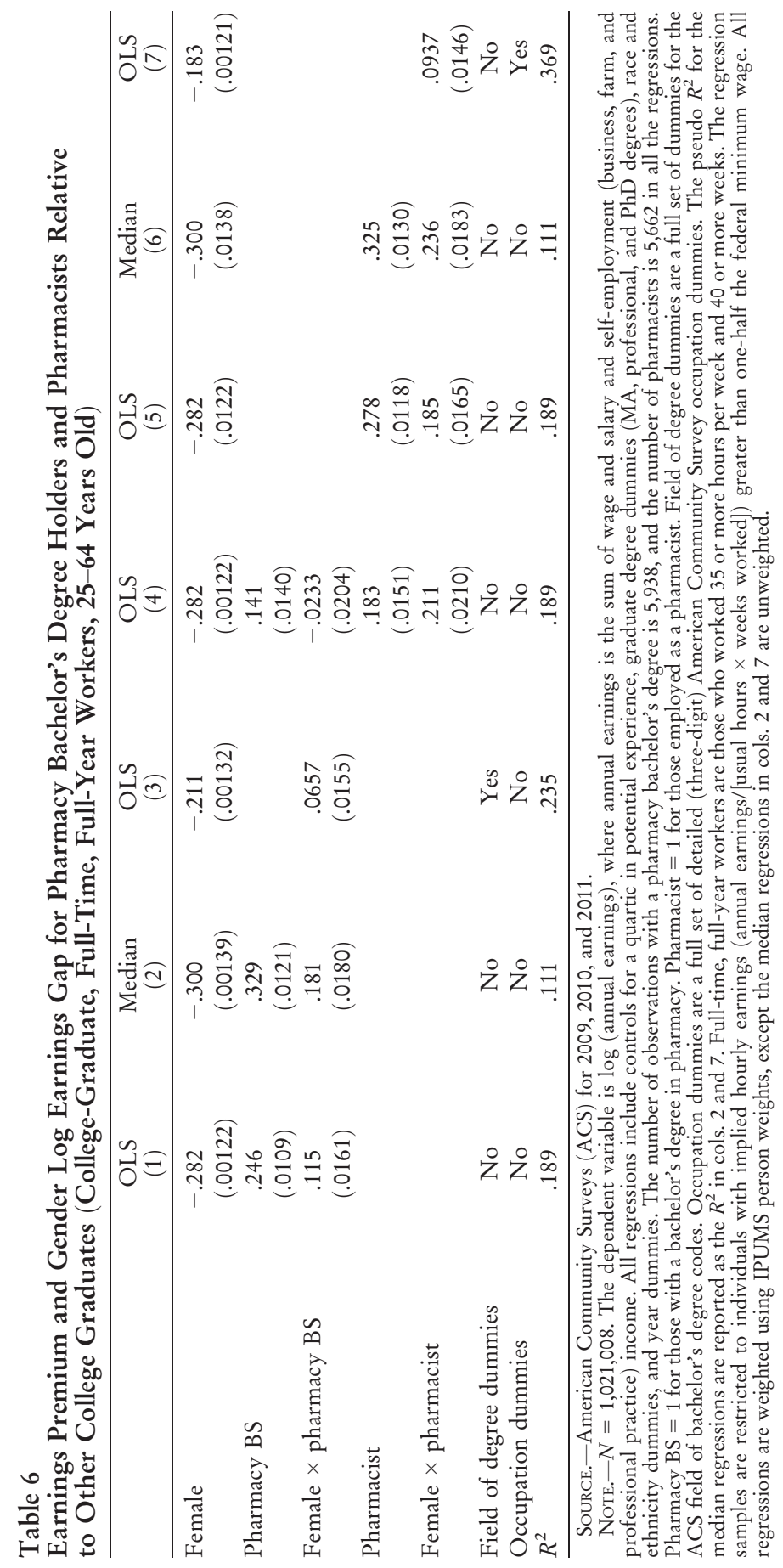

This content downloaded from 128.103.149.052 on July 22, 2016 09:12:20 AM All use subject to University of Chicago Press Terms and Conditions (http://www.journals.uchicago.edu/t-and-c). 
comparable advanced degrees and potential experience. The earnings premium to a pharmacy undergraduate degree largely reflects the returns to working in the pharmacy field. The gender earnings gap, moreover, is significantly smaller in pharmacy than in almost any other college graduate field. ${ }^{39}$

Pharmacy is an egalitarian occupation not only in terms of gender. It also has smaller racial and ethnic wage differentials than are typical of college graduate occupations. ${ }^{40}$ Although women have flocked to pharmacy in recent decades, tabulations from the 2009-11 ACS indicate that blacks and Hispanics are underrepresented in pharmacy relative to their overall share of college graduates. The black and Hispanic representation in pharmacy, however, is similar to that in other health-care professions requiring graduate training.

We also observe in table 7 how pharmacy as a profession for college graduates has evolved. In 1970, male pharmacists typically worked longer hours than other male college graduates (45.6 hours per week vs. 42.0 hours per week) and were far more likely to be self-employed (36.4\% vs. $14.5 \%) .^{41}$ But male pharmacists in 1970 did not earn much more than other comparably trained college graduates (col. 1) and actually had an earnings deficit after conditioning on self-employment and hours worked (cols. 2 and 3). The gender earnings gap was only modestly lower in pharmacy than for other college graduates (col. 1), and female pharmacists with children were heavily penalized for their shorter hours (col. 4).

By 2010, each of these features had greatly changed. Male pharmacists now work shorter hours on average than other male college graduates (41.6 vs. 44.4 hours per week) and are less likely to be self-employed. Pharmacists (especially female pharmacists) currently receive a large earnings premium relative to other college graduates, and the child penalty for

\footnotetext{
${ }^{39}$ The immigrant share of pharmacists of $22.1 \%$ is higher than the overall immigrant share for US college graduates (working full-time, full-year) of $15.6 \%$ in the 2009 to 2011 ACS. The immigrant share is greater for female pharmacists $(24.9 \%)$ than for male pharmacists $(19.2 \%)$. But the smaller gender earnings gap in pharmacy than in other high-education occupations does not reflect an immigrant composition effect. The findings in table 6 of a much smaller gender earnings gap and large wage premium for pharmacists are almost identical when controlling for immigrant status and an interaction of immigrant and female, or when restricting the sample to US natives.

${ }^{40}$ The black-white earnings differential in pharmacy is $0.130 \mathrm{log}$ points narrower (with a SE of 0.039), and the Hispanic-white earnings differential is $0.084 \log$ points narrower (with a SE of 0.047), from regressions analogous to col. 5 of table 6 (using the 2009-11 ACS) expanded to include interactions of "pharmacist" with the race and ethnicity dummies.

${ }^{41}$ These tabulations are from the 1970 Census for employed college graduates 25-64 years old.
} 


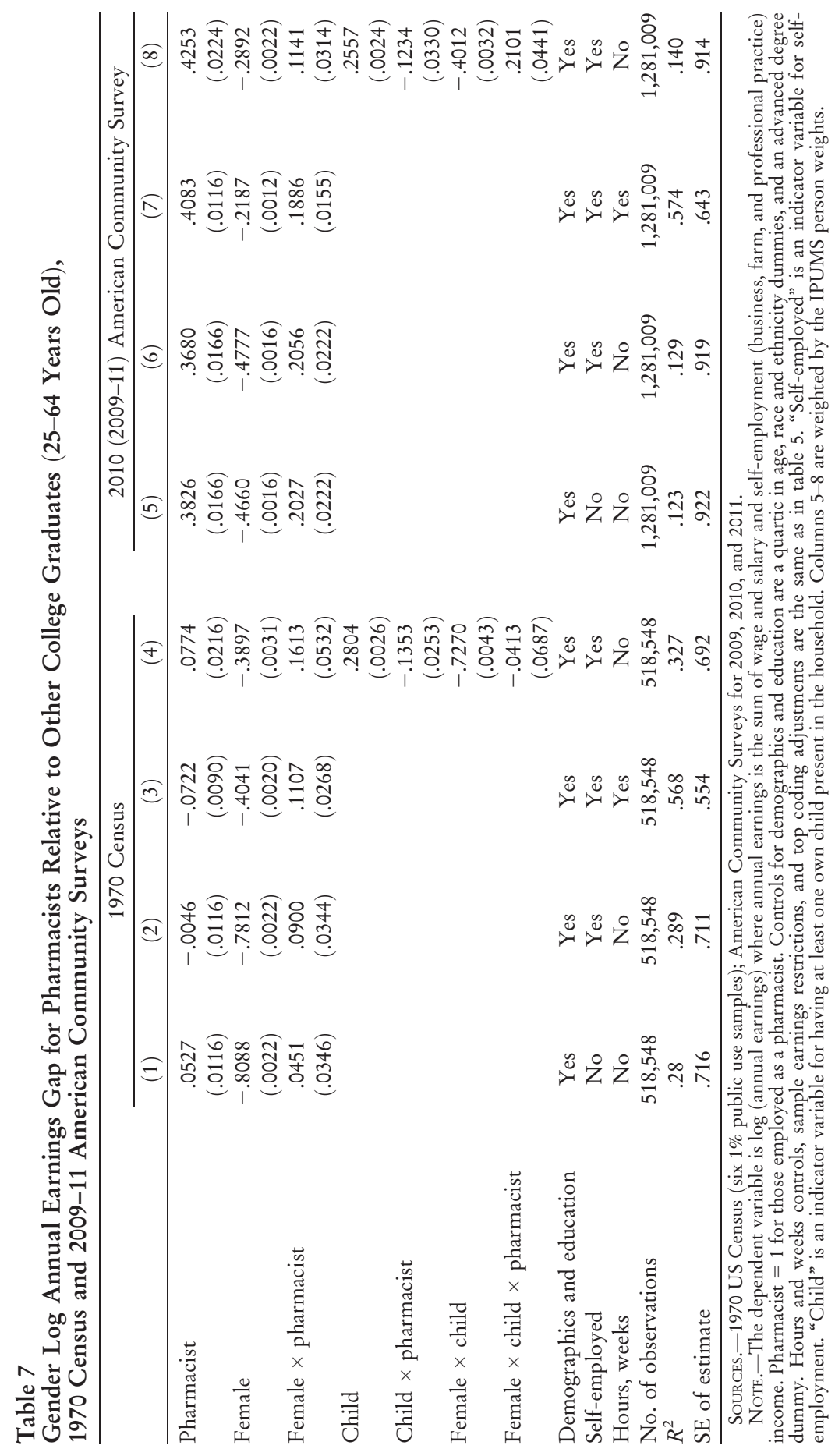

This content downloaded from 128.103.149.052 on July 22, 2016 09:12:20 AM All use subject to University of Chicago Press Terms and Conditions (http://www.journals.uchicago.edu/t-and-c). 
women is lower in pharmacy than in other professions, as seen in columns $5-8$ of table $7 .{ }^{42}$

\section{Why Changes in Pharmacy Benefited Women: A Compensating Differentials Framework}

We have emphasized the roles of various exogenous technological and production changes in the evolution of the pharmacy profession and have downplayed the increased supply of women and changing preferences among pharmacists. The compensating differentials framework is a useful tool for understanding the roles of supply and demand in determining the price of the amenity-temporal flexibility.

Workers sort across occupations and firms because of differences in their preferences for workplace amenities that enable career-family balance. Occupations with a lower cost of workplace flexibility will be demanded relatively more by workers, such as women, who disproportionately value it.

Temporal flexibility in the workplace is an amenity that often entails a wage price to the worker and a cost to the firm. The price of workplace flexibility to the worker will depend on the cost to the firm due to job interruptions, short weeks, part-time work, and work flexibility during the day. Self-employment in professions with office practices (e.g., dentists) or in retail sales (e.g., pharmacists) often requires more hours of work from the owner because of classic agency problems. On the supply side, firms face different costs of providing these amenities.

The choice that employees make is not simply between having workplace flexibility and having none. Instead, they chose how much to "pay" for the amenity. Employees differ in their demand for workplace flexibility and thus their willingness to pay for it. The equilibrium cost of workplace flexibility is the trade-off between earnings and the amenity. It derives from the supply and the demand for the amenity. The labor market equilibrates the two sides of the market (the demand for the amenity and the supply of it) and generates different amounts of the amenity and its costs.

The framework of compensating differentials (also known as equalizing differences) is implicit in our work. ${ }^{43}$ It reveals the impacts of demand-side changes by workers concerning their willingness to pay for the amenity and supply-side changes by firms regarding the shifting costs of providing the amenity. The two types of changes have different effects on relative

${ }^{42}$ The same pattern of little difference in the gender earnings gap in pharmacy vs. other occupations for college graduates in 1970 and a much narrower gender gap in pharmacy in 2010 is found in specifications including three-digit occupation dummies (using 1990 Census occupation codes).

${ }^{43}$ See Rosen (1986). The full model is in app. B. 
earnings and allow us to discriminate between whether the changes we observe were caused largely by changes in tastes or changes in the production technology.

On the supply side of the market, firms are assumed to be heterogeneous in the productivity benefit of the disamenity and thus in the costs of getting rid of it. For some firms (or sectors), the provision of part-time work or temporal flexibility is not costly, whereas for others it is. In equilibrium, the supply of the amenity is equal to the demand for the amenity at the going wage differential.

Two main changes can alter the equilibrium. The first is a labor supply shift. An influx of women (who are assumed to be more willing than men to pay for the amenity) into an occupation will mean that, at the going wage differential, the demand for the amenity will exceed supply and the price of the amenity will rise. A larger wage differential between jobs with and without the amenity will result, the fraction of jobs offering the amenity will increase, and the fraction of men who opt for the amenity will decrease since they are less willing to pay for it.

If, on the other hand, the cost of providing the amenity (or, alternatively, the productive benefit of the disamenity) decreases, more firms would want to offer the amenity at the current wage differential, and pressure will mount for the equilibrating wage differential to decrease to attract more workers to purchase the amenity. More men and more women will shift into flexible jobs, but it is likely that relatively more women will be enticed into these positions.

Individuals with a greater willingness to pay for the amenity, mainly women, earn less than others, mainly men, and a decrease in the cost of supplying the amenity is likely to increase women's relative earnings. An increase in the supply of individuals who value the amenity, mainly women, will increase the equilibrium amount paid for the amenity and tend to decrease women's relative earnings.

The compensating differentials framework includes two cases. A demand-side shift raising the demand for the amenity from an influx of women into the occupation implies (a) an increase in the cost of the amenity and by implication a likely decrease in women's relative earnings, and $(b)$ an increase in the fraction of the total workforce with the amenity (but a decrease in the fraction of men with the amenity since its price rises). A supply-side shift lowering the costs to firms of providing the amenity implies (a) a decrease in the cost of the amenity and by implication a likely increase in women's relative earnings, and $(b)$ an increase in the fraction of the total workforce with the amenity (and an increase in the fraction of men with the amenity since its price decreases). The facts we have described of a decline in the penalty to part-time work and to the premium to ownership and long hours in pharmacy from 1970 to the present are more consistent with the second set of factors. 
One might have expected, ceteris paribus, that improved nonpecuniary benefits from greater temporal flexibility in pharmacy would have reduced the wages of pharmacists. But, as we noted earlier, the earnings of pharmacists have increased substantially relative to most other professions in recent decades. The rapid increase in the demand for pharmacists from advances in pharmaceuticals, the growth of the pharmaceutical industry, and an aging population appear to have outstripped the growth of new pharmacy degree programs and the supply of new pharmacists. The consequence has been the need to provide higher wages, despite better workplace amenities, to attract and retain pharmacists.

\section{Comparisons with Other Professions}

We have emphasized aspects of the pharmacy profession that have made its professionals extremely good substitutes for each other, thereby enhancing the ability of employees to hand off clients and patients with little loss in fidelity. In addition, agency problems in ownership have been circumvented through use of the corporate form. In that way, the premium to long, on-call, and irregular hours has been greatly reduced. We find no penalty to short hours in pharmacy. In addition, women have greatly increased in numbers and the gender gap in pay has declined considerably.

What about other professions, particularly those that share the "big box" aspects of pharmacy? The profession most similar to pharmacy in its level of training, standardization of product, and switch from ownership to the corporate form is optometry. Optometrists are located in some of the same retail chains as are pharmacists, such as Costco, and they are hired in optical retail outlets owned by chains. The increase of women has been even larger in optometry than in pharmacy. The fraction female among optometry graduates increased from less than $5 \%$ in the 1960 s to more than $60 \%$ in the 2000 s. The fraction of male optometrists who are self-employed declined during the past several decades, from $81 \%$ in 1980 to $63 \%$ in 2000 , but it is still considerably higher than in pharmacy. The gender gap in pay has also decreased and is now among the lowest among health-care professionals, although it is somewhat larger than in pharmacy.

Many other health-care professionals also share some of the features of pharmacists. Physicians, veterinarians, and dentists have all experienced decreased self-employment. Dental and veterinary practices have increased in scale, and many are now owned by chains. But, just as in optometry, few have witnessed as large a decrease in self-ownership as has pharmacy. Veterinary medicine has experienced a decrease in on-call and long hours with the increase in regional veterinary hospitals that serve as emergency de- 
partments. In many health-care professions, patients have less of a preference for one doctor over another, but this is probably not to the same degree as in pharmacy, where the service is more standardized. ${ }^{44}$

The legal and financial sectors have seen less change. ${ }^{45}$ Technological or regulatory reasons are occasionally at fault. A trial lawyer must face the jury every trial day, and cameras are not allowed. Idiosyncratic casespecific information is not easily conveyed to substitute lawyers. Traders in the financial sector are generally required to be in their office during market hours. The clients of most MBAs, lawyers, and accountants do not treat these professionals as perfect substitutes for each other, possibly because of nonstandard services, poorly designed information systems, or a culture that emphasizes face-time and personal relationships.

The high degree of substitutability among pharmacists also is suggested by the flatter age-earnings (or experience-earnings) profile for pharmacists than for other comparable professions. Recent pharmacy degree recipients appear to be closer to their peak productivity than novices in other professions. We find that the age-earnings profile for pharmacists is about twothirds as steep as that for the typical college graduate and noticeably (and statistically significantly) flatter than for physicians, lawyers, business occupations, optometrists, veterinarians, and dentists. ${ }^{46}$

Many professions do share some of the characteristics of pharmacists. But pharmacy appears to have a larger number of them that have made its professionals very good substitutes for each other and, in consequence, this has reduced the cost of temporal flexibility.

\section{Conclusion}

Pharmacy today is a highly remunerated profession with a low gender earnings gap and a modest part-time work wage penalty relative to com-

${ }^{44}$ The gender earnings gaps conditional on hours, weeks, and self-employment in specifications comparable to cols. 4 and 8 of table 7, using the 1970 Census and 2009-11 ACS, were modestly narrower for veterinarians and dentists than for pharmacists in 1970 and were significantly wider for veterinarians and dentists in 2010.

${ }^{45}$ Male pharmacists worked longer hours on average than male lawyers in the 1970 Census ( 45.6 vs. 43.7 hours per week), and the gender earnings gap was wider for pharmacists than for the lawyers. The pattern reversed by 2010 with male lawyers working almost 7 more hours per week than male pharmacists and a much larger gender earnings gap for lawyers using the 2009-11 ACS.

${ }_{46}$ These estimates are for full-time, full-year workers aged 25-64 using the 2009-11 ACS. The specifications are analogous to col. 5 of table 6 expanded to include an interaction of age and "pharmacist" as well as main effects and interactions with age for the other occupations. 
parable occupations. It has become a family-friendly profession and is now a female majority profession.

We conclude that increased substitutability among pharmacists is a large part of the reason for these changes. Pharmacists are better able to hand off clients because of uniform training, standardization of products, and extensive use of information technology. The growth of large pharmacy chains, mail-order pharmacies, and hospitals, and the related decline of independent pharmacies, has reduced the premium to ownership. The fraction of pharmacists who work low hours increased, and the hourly earnings of female relative to male pharmacists rose. All of these factors led to the creation of a more family-friendly pharmacy profession.

Earnings of pharmacists today are mainly a function of their hours of work. Conditional on hours of work, female pharmacists earn only 4-7 log points less than comparable male pharmacists (see table 3, cols. 5 and 6). Managers, conditional on hours, earn only about $7 \%$ more than employees, and owners earn about $12 \log$ points more than employees, once again conditional on hours (see table 3, col. 5). In the hourly estimation, owners earn only $5 \log$ points more than employees and managers $3 \log$ points more. Owners work more hours per week relative to employees (7.6 hours for men; 10.5 for women), and the same is true for managers (3.9 hours for men and 8.3 for women). ${ }^{47}$

We find no penalty to working short hours using the PWS data for all years (see table 4, cols. 1 and 2). In our comparison of pharmacists with other college graduates using CPS data, pharmacists earn 26 log points more than other college graduates. Their penalty to part-time employment is just $5 \log$ points, whereas it is $25 \log$ points for the entire group of college graduates (see table 4, col. 3). For women, the penalty to part-time employment for pharmacists is effectively zero, whereas it is $20 \mathrm{log}$ points for all college graduates (see table 4, col. 5). The hourly earnings penalty to part-time work in pharmacy has virtually disappeared during the past 4 decades, whereas it has remained substantial for other college graduates.

But in 1970, before the major changes in the industry, pharmacy was not as highly paid a profession relative to others for college graduates and did not have a narrower gender pay gap. Male pharmacists were more likely to be self-employed and to work longer hours than other male college graduates. Self-employed pharmacists earned a considerable pre-

${ }^{47}$ Differences in hours are computed from a regression of hours in primary job on a cubic in age, and position dummies (manager, owner) on a sample of active pharmacists less than 70 years old. Differences for total hours are somewhat less for men compared with employees (3.4 hours for managers and 6.1 hours for owners) and about the same for women ( 8.0 hours for managers and 10.3 hours for owners). 
mium, and women, particularly those with children, earned far less relative to men than today.

In sum, the position of pharmacist is probably the most egalitarian of all professions in the United States today. The facts we have presented concerning changes in the pharmacy profession are more consistent with the labor market effects of changes in technology and in the structure of the industry. They are less consistent with those stemming solely from an increase in the demand for family-friendly workplace amenities. The changes, moreover, do not appear to have resulted from legislation, antidiscrimination policies, licensing requirements, or regulations specific to the pharmacy profession. ${ }^{48}$ Rather, a host of structural changes outside the realm of the labor market increased the demand for pharmacists and reorganized work in ways that have made pharmacy a more family-friendly and female-friendly profession.

\section{Appendix A}

\section{Data Appendix \\ Pharmacist Workforce Surveys}

The National Pharmacist Workforce Surveys were collected in 3 years: 2000, 2004, and 2009. The surveys were commissioned by the Pharmacy Manpower Project (PMP), now called the Pharmacy Workforce Center. ${ }^{49}$ The PMP comprises the major pharmacy associations (including the AACP, discussed in the text). The Midwest Pharmacy Workforce Research Consortium conducted the surveys and designed the project. The Consortium contains six principal investigators from five universities.

The primary purpose of the surveys was to collect reliable information on demographic and work characteristics of the pharmacist workforce in the United States. The project obtained information from a nationally representative sample of pharmacists. The principals developed a survey questionnaire covering employment status and situation (working or not, setting, position, years employed and in current position), compensation and hours worked, work environment (hours the prescription department is staffed, time spent in professional activities, number of staff working, workload, and perceptions of workload and workload impact), future work plans (leave or stay with current employment and reasons therefore), and individual demographic background information.

\footnotetext{
${ }^{48}$ See Kleiner and Krueger (2013) on the impacts of occupational licensing on labor market outcomes.

${ }^{49}$ Some of the wording in this appendix closely follows the description of the surveys in the sources listed at the end.
} 
The survey methodology and the size of the project for each year is as follows. In each year, the data were collected via mailed survey using KM Lists, Inc., a national medical marketing data warehouse that maintains a list of about 250,000 licensed pharmacists in the United States.

2000: Data for 2000 were collected from a random sample of 5,000 licensed pharmacists. The overall response rate (subtracting surveys that were undeliverable) was $46 \%(2,250 / 4,895)$, and the net useable response rate was $43 \%(2,092 / 4,895)$.

2004: Data for 2004 were collected from a random sample of 6,000 pharmacists. The principals randomly chose 5,000 from this list and retained a hold-back sample of 1,000 . To compensate for initial bad addresses, a replacement sample of 435 pharmacists was randomly chosen from the hold-back group. Usable forms were received from about 1,500, for a response rate of about $34 \%$. The survey design was almost identical to that in 2000 .

2009: Questions comprising each section of the 2009 survey were taken from previous workforce surveys, and most of the items used for the 2009 survey also were used in 2000 and 2004. The initial size of the group was smaller in 2009 than in previous years but better methods were employed to obtain a higher response rate. A randomly selected sample of 3,000 names yielded about 2,667 with usable addresses. Surveys from almost 1,400 pharmacists were returned, or about a $51 \%$ response rate.

The 2009 survey has fewer young pharmacists than the other two surveys, possibly because of the increase in the fraction with PharmD degrees. Because of the lower fraction of those in their twenties, few have very young children relative to the previous years.

The three surveys were analyzed separately by the principals in a series of publications. One of them, Jon Schommer, and a graduate student merged the three surveys and created a data set with largely consistent variables. Schommer made the data available to us in 2011, and we cleaned it further.

\section{Appendix B}

\section{Theory Appendix}

A. Compensating Differentials Framework of Gender Differences in Earnings and Occupations

Many professions have increased their workplace flexibility in the past few decades, and some occupations and firms are more enabling of family than are others. What these statements translate into is that occupations and professions differ in the pecuniary penalties to certain characteristics that are considered family-friendly amenities. 
What happens in the labor market when there is a shift in worker demand for greater flexibility? What happens when there is a technological change that reduces the costs of providing such flexibility? To explore these questions, we develop a model of an occupation having an amenity that is costly to offer.

We model the provision of the amenity, such as workplace flexibility, by borrowing from Sherwin Rosen's (1986) model of "compensating differentials," which in turn is a formalization of ideas dating back to Adam Smith. Our framework is, as well, a generalization of that in Mincer and Polachek (1974), which emphasizes the impact of career interruptions for the gender wage gap and occupational choice. Whereas Mincer and Polachek treat the mix of jobs as given, we make it endogenous. The model will reveal the differential impacts of an increase in the demand for the amenity (or a decreased willingness to work with the disamenity) and a decrease in the cost of providing the amenity (or reducing the disamenity).

Consider that various aspects of work are disamenities to some but are not overly bothersome to others. These disamenities can include workplace hazards, but we focus on workplace flexibility in all its forms. The ability to shift hours during the day may be highly valued by some but not worth much to others. The fact that some professions heavily penalize job interruptions and disproportionately tax short hours may be more important to some workers than to others. The same is true with other aspects of workplace family friendliness including the provision of on-site daycare and paid leave policy.

The amenity we consider is job flexibility, and it is modeled as a discrete variable. Jobs are either inflexible or flexible. The inflexible jobs come with a disamenity $(D=1)$. Alternatively, jobs can be flexible and not have the disamenity $(D=0)$.

Workers are assumed to be heterogeneous in their tastes for the disamenity $(D)$. If $Z=$ the compensating variation required for indifference between $D=1$ and $D=0$ and $C=$ worker's consumption, then $U(C, D) \rightarrow$ $U\left(C^{*}, 1\right)=U\left(C_{0}, 0\right)$ and $Z=\left(C^{*}-C_{0}\right)$. Here $Z$ is continuously distributed $Z \sim G(Z)$. The compensating differential in earnings between a job with the disamenity and one without is $W=[W(D=1)-W(D=0)]>0$.

If $G(Z)$ is given by the distribution drawn in figure $\mathrm{B} 1$, part $A$, and the compensating differential for the disamenity in the occupation or firm is $\Delta W^{*}$, all individuals to the right of $\Delta W^{* *}$ will opt for the job without the disamenity. The offered wage difference of $\Delta W^{*}$ is insufficiently high for those to the right of the dashed line to be fully compensated for the disamenity. Those to the left, however, express a willingness to take the job with the disamenity since the wage difference is higher than the amount that would make them indifferent between having and not having the disamenity. That is, a worker chooses the disamenity, $D=1$, if $\Delta W>Z$. 

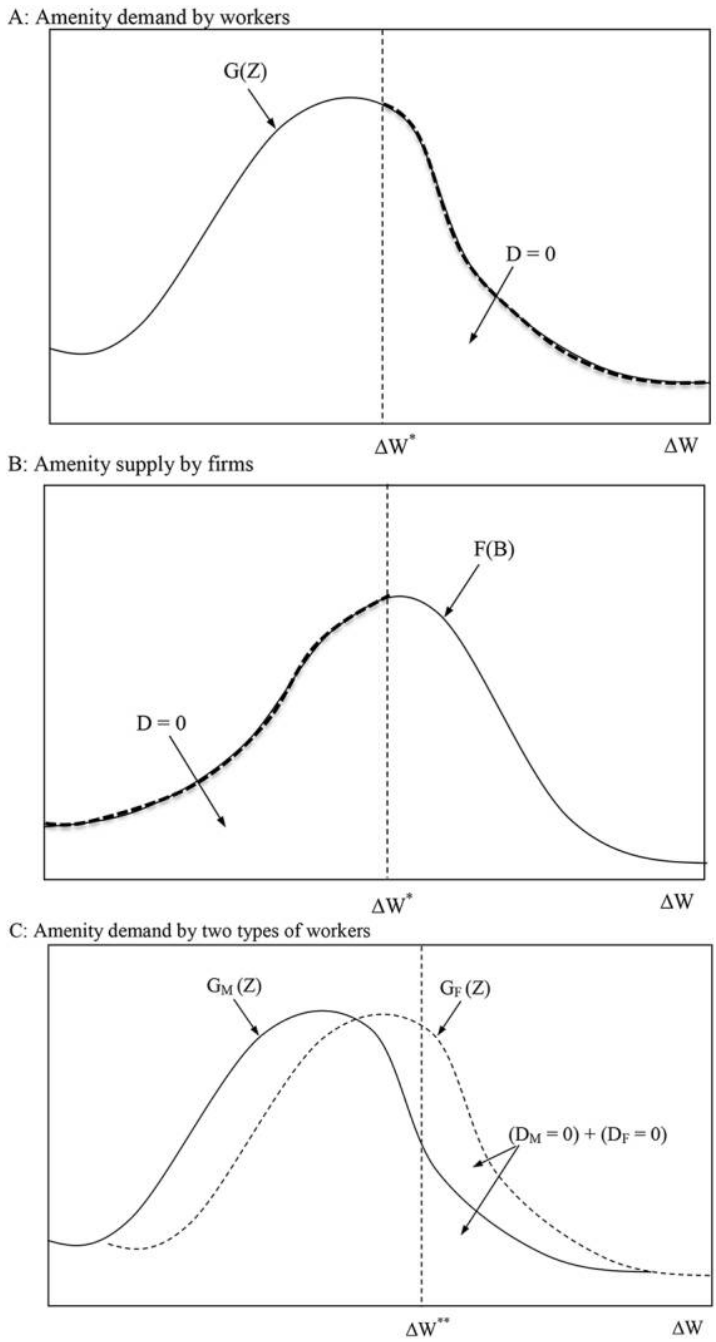

FIG. B1.- Schematic representation of the market for an occupational amenity $(D=0) ; A$, amenity demand by workers; $B$, amenity supply by firms; $C$, amenity demand by two types of workers. $D=1$ represents the disamenity, and $D=0$ represents the amenity. $G(Z)$ is the distribution of $Z$ (the compensating variation required for indifference between $D=1$ and $D=0$ ) and $F(B)$ is the distribution of $B$ (the productivity benefit of the disamenity). $G_{M}(Z)$ and $G_{F}(Z)$ are the distribution of $\mathrm{Z}$ for males and females, respectively. $\Delta \mathrm{W}$ is the compensating differential between the occupation without the amenity (i.e., with the disamenity) and the one with the amenity (i.e., without the disamenity). For workers, it is a compensating payment; for firms, it is a benefit (a negative cost). $\Delta W^{*}$ and $\Delta W^{* * *}$ are hypothetical earnings differentials that workers receive and firms pay. 
Similarly, the firms' technologies that produce the amenity (or that ameliorate the disamenity) are assumed to be distributed continuously. On the supply side of the market, firms are assumed to be heterogeneous in the productivity benefit of the disamenity $(B)$ and thus in the costs of getting rid of it, such that $B \sim F(B)$. If $F(B)$ is given by the distribution drawn in figure $\mathrm{B} 1$, part $B$, and $\Delta W^{*}$ is the given wage differential the firms are paying, firms to the left of $\Delta W^{*}$ would provide the amenity and the firms to the right of the dashed line would not. The firm chooses to have jobs with the disamenity, $D=1$, if $\Delta W<B$.

The market equilibrium for the amenity occurs when its supply equals its demand. In equilibrium, the share of jobs with the amenity $(D=0)$ is $[1-G(\Delta W)]=F(\Delta W)$. In the case drawn in figure B1, the supply of the amenity appears to be equal to the demand at the going wage differential. If it were greater than demand, the price of the amenity would fall and if it were less than demand, the price of the amenity would rise.

The model can be elaborated on by dividing workers into two groups, for example, males and females. As depicted in figure B1, part $C$, the distribution for women, $G_{F}(Z)$, lies to the right of that for men, $G_{M}(Z)$. At every $\Delta W$, and at $\Delta W^{* *}$ in particular, women demand more of the amenity than men, and men, instead, walk away with the higher salary and the disamenity.

Two main changes can alter the equilibrium. The first is a labor supply shift. An influx of women into an occupation (who presumably are more willing than men to pay for the amenity) will lead to a rightward shift in the distribution $G(Z)$. At the going wage differential, demand will exceed supply, and the price of the amenity will rise, in consequence. A larger wage differential between jobs with and without the amenity will result, the fraction of jobs offering the amenity will increase, and a greater fraction of men who opt for the amenity will decrease since it has become more expensive.

If, on the other hand, the cost of providing the amenity (or, alternatively, the productive benefit of the disamenity) decreases, the distribution $F(B)$ would shift to the left. At the current wage differential, more firms would want to offer the amenity $(D=0)$ and pressure will mount for $\Delta W$ to decrease to attract more workers to purchase it. More men and women within the occupation will shift into flexible jobs since the price of the amenity is lower.

In sum, the framework shows that individuals with a greater willingness to pay for the amenity earn less than others and that a decrease in the cost of supplying the amenity increases their relative earnings. An increase in the supply of individuals to the occupation who value the amenity will increase the equilibrium amount paid for the amenity and widen the gap in earnings between those with a lower valuation of the amenity (disproportionately men) and those with a higher valuation of the amenity (disproportionately women). 
Table B1

Respondents by Year and Distribution by Sex and Age in the Pharmacist Workforce Surveys Merged Data

\begin{tabular}{|c|c|c|c|c|c|c|}
\hline \multirow[b]{2}{*}{ Age Group } & \multicolumn{3}{|c|}{ Fraction Female } & \multicolumn{3}{|c|}{ Fraction by Age Group } \\
\hline & 2000 & 2004 & 2009 & 2000 & 2004 & 2009 \\
\hline $25-29$ & .751 & .751 & .714 & .0999 & .0509 & .0146 \\
\hline $30-34$ & .629 & .629 & .713 & .129 & .110 & .0838 \\
\hline $35-39$ & .633 & .633 & .701 & .137 & .110 & .106 \\
\hline $40-44$ & .566 & .566 & .572 & .147 & .110 & .119 \\
\hline $45-49$ & .324 & .324 & .532 & .144 & .144 & .110 \\
\hline $50-54$ & .261 & .261 & .336 & .0971 & .139 & .160 \\
\hline $55-59$ & .171 & .171 & .280 & .0805 & .104 & .141 \\
\hline $60-64$ & .143 & .143 & .191 & .0520 & .0760 & .109 \\
\hline$>64$ & .0996 & .137 & .140 & .115 & .156 & .156 \\
\hline Totals with sex, age by year & 2,197 & 1,542 & 1,386 & 2,185 & 1,515 & 1,372 \\
\hline
\end{tabular}

\section{References}

Altonji, Joseph G., Erica Blom, and Costas Meghir. 2012. Heterogeneity in human capital investments: High school curriculum, college major, and careers. Annual Review of Economics 4, no. 1:185-223.

Bertrand, Marianne, Claudia Goldin, and Lawrence F. Katz. 2010. Dynamics of the gender gap for young professionals in the financial and corporate sectors. American Economic Iournal: Applied Economics 2, no. 3:228-55.

Bottero, Wendy. 1992. The changing face of the professions? Gender and explanations of women's entry to pharmacy. Work, Employment, and Society 6, no. 3:329-46.

Bourdon, Olivier, Catherine Ekeland, and Françoise Brion. 2008. Pharmacy education in France. American Iournal of Pharmaceutical Education 72 , no. 6, article 132.

Fulda, Thomas R. 1976. Prescription drug data summary, 1974. US Department of Health, Education, and Welfare, publication no. (SSA) 76-11928. Baltimore: Social Security Administration.

Goldin, Claudia. 2014. A grand gender convergence: Its last chapter. American Economic Review 104, no. 4:1091-1119.

Goldin, Claudia, and Lawrence F. Katz. 2011. The cost of workplace flexibility for high-powered professionals. Annals of the American Academv of Political and Social Science 638, no. 1:45-67.

Henderson, Metta Lou. 2002. American women pharmacists: Contributions to the profession. New York: Pharmaceutical Products.

Kapantais, Gloria M. 1982. Summary data from the National Inventory of Pharmacists: United States, 1978-79. NCHS advance data, no. 85 (October 8), 1-7, Vital Health Statistics of the National Center for Health Statistics, US Department of Health and Human Services. 
Kleiner, Morris M., and Alan B. Krueger. 2013. Analyzing the extent and influence of occupational licensing on the labor market. Lournal of Labor Economics 31, no. 2, pt. 2:S173-S202.

Knapp, Katherine K., Marianne J. Koch, Linda Norton, and Michael A. Mergener. 1992. Work patterns of male and female pharmacists: A longitudinal analysis, 1959-1989. Evaluation and the Health Professions 15, no. 2:231-49.

Kremers, Edward, Glenn Sonnedecker, and George Urdang. 1986. Kremers and Urdang's history of pharmacy. 4th ed. Madison, WI: American Institute of the History of Pharmacy.

Lluch, Maria, and Panos Kanavos. 2010. Impact of regulation of community pharmacies on efficiency, access and equity: Evidence from the UK and Spain. Health Policy 95, nos. 2-3:245-54.

Midwest Pharmacy Workforce Research Consortium. 2000. Final report of the National Pharmacist Workforce Survey, 2000. Alexandria, VA: Pharmacy Manpower Project, Inc.

- 2005. Final report of the 2004 National Sample Survey of the Pharmacist Workforce to determine contemporary demographic and practice characteristics. Alexandria, VA: Pharmacy Manpower Project, Inc.

2010. Final report of the 2009 National Pharmacist Workforce Survey to determine contemporary demographic and practice characteristics. Alexandria, VA: Pharmacy Manpower Project, Inc.

Miller, Dennis. 2012. Pharmacy exposed: 1,000 things that can go deadly wrong at the drugstore. CreateSpace Independent Publishing Platform.

Mincer, Jacob, and Solomon Polachek. 1974. Family investments in human capital. Iournal of Political Economy 82, no. 2, pt. 2:S76-S108.

Northrup, Herbert R., Douglas F. Garrison, and Karen M. Rose. 1979. Manpower in the retail pharmacy industry. Philadelphia: University of Pennsylvania, Wharton School Industrial Research Unit.

Rosen, Sherwin. 1986. The theory of equalizing differences. In The handbook of labor economics, vol. 1, ed. Orley Ashenfelter and Richard Layard, 641-92. Amsterdam: Elsevier.

Sasser, Alicia C. 2005. Gender differences in physician pay: Tradeoffs between career and family. Iournal of Human Resources 40, no. 2:477504.

US Department of Education, National Center for Education Statistics. Various years. Digest of education statistics. http://nces.ed.gov/programs /digest/.

US Department of Health and Human Services. 2000. Report to Congress: The pharmacist workforce: A study of the supply and demand for pharmacists (December). Washington, DC: US Government Printing Office.

US Department of Health, Education, and Welfare. 1978. Pharmacy manpower resources. Washington, DC: US Government Printing Office. 
US Department of Health, Education, and Welfare, Public Health Service, Health Services, and Mental Health Administration. 1969. Pharmacy manpower, United States, 1966. Washington, DC: US Government Printing Office.

Wood, Robert G., Mary E. Corcoran, and Paul N. Courant. 1993. Pay differences among the highly paid: The male-female earnings gap in lawyers' salaries. Lournal of Labor Economics 11, no. 3:417-41. 